The Astrophysical Journal Supplement Series, 111:339-355, 1997 July

(C) 1997. The American Astronomical Society. All rights reserved. Printed in U.S.A.

\title{
ELECTRON-ION RECOMBINATION RATE COEFFICIENTS, PHOTOIONIZATION CROSS SECTIONS, AND IONIZATION FRACTIONS FOR ASTROPHYSICALLY ABUNDANT ELEMENTS. I. CARBON AND NITROGEN
}

\author{
Sultana N. Nahar and Anil K. Pradhan \\ Department of Astronomy, Ohio State University, Columbus, OH 43210 \\ Received 1996 October 7; accepted 1997 January 24
}

\begin{abstract}
We present a comprehensive and self-consistent set of new atomic data for ionization balance in radiatively and collisionally ionized astrophysical plasmas. Complex resonant phenomena resulting in rapid energy variation in the cross sections for photoionization and recombination require accurate and largescale calculations, as reported. Another new development is the consideration of the unified nature of the recombination process in an ab initio manner, via resonances embedded in the electron-ion continua, which have been heretofore considered as separate processes of radiative recombination and dielectronic recombination. A single set of total electron-ion recombination rate coefficients is thereby obtained as a function of electron temperature. The present calculations also meet the hitherto neglected, but theoretically essential, criterion of self-consistency between the rates for the inverse processes of photoionization and recombination, ensured by describing all atomic processes with an identical set of eigenfunction expansion within the close-coupling approximation using the $\boldsymbol{R}$-matrix method. Photoionization cross sections and total electron-ion recombination rate coefficients for the carbon and nitrogen isonuclear sequences, $\mathrm{C}_{\mathrm{I}}-\mathrm{C}$ VI and N I-N VII, are presented. Ionization fractions in coronal equilibrium are also computed. The present photoionization cross sections have been calculated using more extensive eigenfunction expansions than those in the Opacity Project. In addition to the total photoionization and recombination data, state-specific cross sections are also obtained for a large number of excited states for non-LTE models. Complete data sets are available electronically.
\end{abstract}

Subject headings: atomic data - atomic processes - plasmas

\section{INTRODUCTION}

Ionization balance is the primary feature in astrophysical models of diffuse, nebular objects. The two most common assumptions for the ionization conditions in the plasma are (1) photoionization equilibrium and (2) collisional or coronal equilibrium (Osterbrock 1989). The dominant ionizing process in the first case is photoionization from the radiation field in the source, and in the second case, electron impact ionization in usually optically thin plasmas (such as the solar corona). Both ionization processes are sought to be balanced by the inverse process of electron-ion recombination in the ambient medium characterized by a given electron temperature, usually in terms of a Maxwellian distribution, and an electron density. The two sets of ionization balance equations may be written as

$$
\begin{gathered}
\int_{v_{0}}^{\infty} \frac{4 \pi J_{v}}{h v} N\left(X^{z}\right) \sigma_{\mathrm{PI}}\left(v, X^{z}\right) d v=\sum_{j} N_{e} N\left(X^{z+1}\right) \alpha_{R}\left(X_{j}^{z} ; T\right), \\
C_{I}\left(T, X^{z}\right) N_{e} N\left(X^{z}\right)=\sum_{j} N_{e} N\left(X^{z+1}\right) \alpha_{R}\left(X_{j}^{z} ; T\right),
\end{gathered}
$$

where $\alpha_{R}\left(X_{j}^{z} ; T\right)$ is the total electron-ion recombination rate coefficient of the recombined ion of charge $z, X_{j}^{z}$, to state $j$ at electron temperature $T, C_{I}$ is the rate coefficient for electron impact ionization, and $\sigma_{\mathrm{PI}}$ is the photoionization cross section evaluated at photon frequency $v$ and convoluted with the isotropic radiation density $J_{v}$ of the source; $N_{e}$, $N\left(X^{z+1}\right)$, and $N\left(X^{z}\right)$ are the densities for the free electrons, and the recombining and recombined ions, respectively.

Implicit in these equations is the assumption that the ionization rates on the left-hand side refer to the ground state of the ion. This condition is predicated on the assump- tion that the radiative and collisional processes proceed on faster timescales than photoionization and recombination. Substantial departures from these equilibrium conditions may result at high densities where some excited states are significantly populated or in LTE. The sum on the righthand side extends over the infinite number of excited states into which recombinations can take place, depending on the temperature.

Unlike previous works, the present work seeks to satisfy the photoionization equilibrium condition (eq. [1]) in a fundamentally consistent manner: the photoionization and recombination calculations are carried out using the same set of atomic eigenfunctions. Furthermore, as the detailed photoionization cross sections include autoionizing resonances in an ab initio manner, the electron-ion recombination rates subsume both the radiative and the dielectronic recombination processes, which have been treated separately in previous works using different methods.

In the coronal approximation (eq. [2]) some of the previous calculations for ionization fractions are Jacobs et al. (1980, and references therein), Shull \& van Steenberg (1982a, 1982b), Arnaud \& Rothenflug (1985), and Sutherland \& Dopita (1993). In general, most of the electron-ion recombination data employed in the earlier works are based on radiative recombination (RR) rates (e.g., Aldrovandi \& Pequignot 1973) derived from photoionization cross sections that neglect the now well-established phenomenon of autoionizing resonances (e.g., Reilman \& Manson 1979), and on dielectronic recombination (DR) rates derived from the Burgess general formula (Burgess 1965), but incorporating the important advances made in the treatment of DR by Jacobs et al. (1980), who showed the effect of autoionization into excited states, and later by 
Nussbaumer \& Storey (1983), who established the significant contribution from near-threshold autoionizing resonances resulting in a low-temperature bump (in addition to the usual high-temperature rise in the DR rate). For electron impact ionization, the latest experimental and theoretical data were assessed by Bell et al. (1983) for light atoms and ions up to the oxygen sequence, and by Lennon et al. (1988) for the heavier elements, flourine to nickel; these authors also provided fitting formulae to obtain the collisional rate coefficients from the recommended data, including the important effect of excitation autoionization, which can enhance the background ionization cross sections by large factors. In the present calculations for the coronal ionization fractions, we use the new ionization data together with our unified electron-ion recombination rates reported herein and in previous works by the authors (e.g., Nahar \& Pradhan 1995, hereafter NP; Nahar 1996b).

The calculations are carried out in the close-coupling approximation using the $\boldsymbol{R}$-matrix method developed for the Opacity Project and the Iron Project (Berrington et al. 1987; Hummer et al. 1993) and the extended codes (Nahar \& Pradhan 1994). These large-scale computations entail photoionization, electron impact excitation, and recombination processes. In our previous works the calculations were done mainly along isoelectronic sequences to facilitate algebraic manipulations enabled by using the same target wave function expansion for all ions in the sequence. Some calculations were also done for important systems such as Fe I-Fe III, S II-S III, and Si I-Si II (Nahar 1995, 1996a, 1996b; Nahar, Bautista, \& Pradhan 1997a). However, for full ionization balance calculations all ionization stages of a given element, i.e., along an isonuclear sequence, must be considered since the ionic fractions depend on coupled ionization stages. It is the aim of this and future works to enable such calculations for astrophysically abundant elements, beginning with carbon and nitrogen.

\section{THEORY AND COMPUTATIONS}

The theoretical details for photoionization calculations are essentially as described by the Opacity Project Team (1995). The details of the unified treatment for the total electron-ion recombination are given in Nahar \& Pradhan (1994) and NP. Some of the main points are sketched in the subsections below.

\subsection{Total and Partial Photoionization Cross Sections}

The calculations for the photoionization cross sections, $\sigma_{\mathrm{PI}}$, are carried out in the close coupling (CC) approximation using the $\boldsymbol{R}$-matrix method, as in the work of the Opacity Project (OP; Seaton 1987; Berrington et al. 1987; Seaton et al. 1994). Each atom or ion is represented in terms of the eigenfunctions of the "core" or the "target" ion, coupled to a "free" electron wave function. For example, $\mathrm{C}_{\mathrm{I}}$ is represented in terms of an expansion over the target states of $\mathrm{C}$ II, which when coupled with the free electron wave functions yield both the $\mathrm{C}$ I bound state wave functions as well as the $(e+\mathrm{C}$ II) continuum wave functions. The photoionization cross section, $\sigma_{\mathrm{PI}}$, is then obtained via the dipole matrix element between the bound and the continuum states. Present computations for the $\sigma_{\mathrm{PI}}$ employ larger eigenfunction expansions for most of the ions than in the OP. The target wave functions are obtained using the atomic structure code SUPERSTRUCTURE (Eissner, Jones, \& Nussbaumer 1974). Tables 1 and 2 present the
TABLE 1

TARget Terms for Eigenfunction Expansions of Carbon Ions

\begin{tabular}{|c|c|c|c|c|c|c|c|c|c|}
\hline \multicolumn{2}{|c|}{$\begin{array}{l}\mathrm{C}_{\text {II }} \\
(1)\end{array}$} & \multicolumn{2}{|c|}{$\begin{array}{l}\text { C III } \\
(2)\end{array}$} & \multicolumn{2}{|c|}{$\begin{array}{c}\text { C IV } \\
(3)\end{array}$} & \multicolumn{2}{|c|}{$\begin{array}{l}\mathrm{C} \mathrm{v} \\
\text { (4) }\end{array}$} & \multicolumn{2}{|c|}{$\begin{array}{l}\mathrm{C} \text { VI } \\
(5)\end{array}$} \\
\hline $2 s^{2} 2 p$ & ${ }^{2} P^{o}$ & $2 s^{2}$ & ${ }^{1} S$ & $1 s^{2} 2 s$ & ${ }^{2} S$ & $1 s^{2}$ & ${ }^{1} S$ & $1 s$ & ${ }^{2} S$ \\
\hline $2 s 2 p^{2}$ & ${ }^{4} P$ & $2 s 2 p$ & ${ }^{3} P^{o}$ & $1 s^{2} 2 p$ & ${ }^{2} P^{o}$ & $1 s 2 s$ & ${ }^{3} S$ & $2 s$ & ${ }^{2} S$ \\
\hline $2 s 2 p^{2}$ & ${ }^{2} D$ & $2 s 2 p$ & ${ }^{1} P^{o}$ & $1 s^{2} 3 s$ & ${ }^{2} S$ & $1 s 2 p$ & ${ }^{3} P^{o}$ & $2 p$ & ${ }^{2} P^{o}$ \\
\hline $2 s 2 p^{2}$ & ${ }^{2} S$ & $2 p^{2}$ & ${ }^{3} P$ & $1 s^{2} 3 p$ & ${ }^{2} P^{o}$ & $1 s 2 s$ & ${ }^{1} S$ & $3 s$ & ${ }^{2} S$ \\
\hline $2 s 2 p^{2}$ & ${ }^{2} P$ & $2 p^{2}$ & ${ }^{1} D$ & $1 s^{2} 3 d$ & ${ }^{2} D$ & $1 s 2 p$ & ${ }^{1} P^{o}$ & $3 p$ & ${ }^{2} P^{o}$ \\
\hline $2 s^{2} 3 s$ & ${ }^{2} S$ & $2 p^{2}$ & ${ }^{1} S$ & $1 s^{2} 4 s$ & ${ }^{2} S$ & $1 s 3 s$ & ${ }^{3} S$ & $3 d$ & ${ }^{2} D$ \\
\hline $2 s^{2} 3 p$ & ${ }^{2} P^{o}$ & $2 s 3 s$ & ${ }^{3} S$ & $1 s^{2} 4 p$ & ${ }^{2} P^{o}$ & $1 s 3 s$ & ${ }^{1} S$ & $4 f$ & ${ }^{2} F^{o}$ \\
\hline $2 p^{3}$ & ${ }^{4} S^{o}$ & $2 s 3 s$ & ${ }^{1} S$ & $1 s^{2} 4 d$ & ${ }^{2} D$ & $1 s 3 p$ & ${ }^{3} P^{o}$ & $4 d$ & ${ }^{2} D$ \\
\hline $2 p^{3}$ & ${ }^{2} D^{o}$ & $2 s 3 p$ & ${ }^{1} P^{o}$ & $1 s^{2} 4 f$ & ${ }^{2} F^{o}$ & $1 s 3 d$ & ${ }^{3} D$ & $4 p$ & ${ }^{2} P^{o}$ \\
\hline $2 p^{3}$ & ${ }^{2} P^{o}$ & $2 s 3 p$ & ${ }^{3} P^{o}$ & & $\ldots$ & $1 s 3 d$ & ${ }^{1} D$ & $4 s$ & ${ }^{2} S$ \\
\hline ... & .. & $2 s 3 d$ & ${ }^{3} D$ & $\ldots$ & $\ldots$ & $1 s 3 p$ & ${ }^{1} P^{o}$ & $\ldots$ & $\ldots$ \\
\hline$\ldots$ & & $2 s 3 d$ & ${ }^{1} D$ & & & $\ldots$ & & & \\
\hline \multicolumn{2}{|c|}{$10-\mathrm{CC}$} & \multicolumn{2}{|c|}{ 12-CC } & \multicolumn{2}{|c|}{ 9-CC } & \multicolumn{2}{|c|}{$11-\mathrm{CC}$} & \multicolumn{2}{|c|}{$10-\mathrm{CC}$} \\
\hline \multirow{2}{*}{\multicolumn{2}{|c|}{$\begin{array}{l}\text { OP: } 10-\mathrm{CC} \\
=246\end{array}$}} & \multicolumn{2}{|c|}{ 6-CC } & \multicolumn{2}{|c|}{$5-\mathrm{CC}$} & \multicolumn{2}{|c|}{$2-\mathrm{CC}$} & \multicolumn{2}{|c|}{$5-\mathrm{CC}$} \\
\hline & & \multirow{2}{*}{\multicolumn{2}{|c|}{$2 s^{2} 2 p\left({ }^{2} P^{o}\right)$}} & \multirow{2}{*}{\multicolumn{2}{|c|}{$\begin{array}{c}114 \\
2 s^{2}\left({ }^{1} S\right)\end{array}$}} & \multirow{2}{*}{\multicolumn{2}{|c|}{$\begin{array}{c}53 \\
1 s^{2} 2 s\left({ }^{2} S\right)\end{array}$}} & \multirow{2}{*}{\multicolumn{2}{|c|}{$\begin{array}{c}108 \\
1 s^{2}\left({ }^{1} S\right)\end{array}$}} \\
\hline \multicolumn{2}{|c|}{$E_{g}=2 s^{2} 2 p^{2}\left({ }^{3} P\right)$} & & & & & & & & \\
\hline
\end{tabular}

NoTE.-Target terms for the eigenfunction expansions of carbon ions: the spectroscopic and correlation configurations, and the values of $\lambda$ parameter are given below. For each ion, $E_{g}$ is the ground state, and $N_{\text {bnd }}$ is the total number of calculated bound states that couple to the target ground state.

C II.-Spectroscopic: $1 s^{2} 2 s^{2} 2 p, 1 s^{2} 2 s 2 p^{2}, 1 s^{2} 2 p^{3}$. Correlation: $1 s^{2} 2 s^{2} 3 s$, $1 s^{2} 2 s^{2} 3 p, 1 s^{2} 2 s^{2} 3 d, 1 s^{2} 2 s 2 p 3 s, 1 s^{2} 2 s 2 p 3 p, 1 s^{2} 2 s 2 p 3 d, 1 s^{2} 2 p^{2} 3 s, 1 s^{2} 2 p^{2} 3 p$, $1 s^{2} 2 p^{2} 3 d, 1 s^{2} 2 s 3 d^{2}, 1 s^{2} 2 s 3 p 3 d, 1 s^{2} 2 s 3 s 3 p, 1 s^{2} 2 s^{2} 4 s, 1 s^{2} 2 s^{2} 4 p, 1 s^{2} 2 s^{2} 4 d$, $1 s^{2} 2 p^{2} 4 s, \quad 1 s^{2} 2 s 3 s^{2}, \quad 1 s^{2} 2 p 3 s 3 p, \quad 1 s^{2} 2 p 3 s 3 d$. Scaling parameter, $\lambda$ : 1.44076(1s), 1.32788(2s), 1.19275(2p), 2.3707(3s), 2.12564(3p), - 1.00631(3d), $-0.91501(4 s),-0.823(4 p),-1.09317(4 d)$.

C III.-Spectroscopic: $1 s^{2} 2 s^{2}, 1 s^{2} 2 s 2 p, 1 s^{2} 2 p^{2}, \quad 1 s^{2} 2 s 3 s, \quad 1 s^{2} 2 s 3 p$, $1 s^{2} 2 s 3 d$. Correlation: $1 s^{2} 2 p 3 s, 1 s^{2} 2 s 4 s, 1 s^{2} 2 s 4 p, 1 s^{2} 2 p 3 p$. Scaling parameter, $\lambda: 1.4(1 s), 1.4(2 s), 1.127(2 p), 1.2(3 s), 1.1(3 p), 1.1(3 d), 10.6115(4 s)$, 4.37106(4p), 4.1(4d).

C IV.-Spectroscopic: $1 s^{2} 2 s, 1 s^{2} 2 p, 1 s^{2} 3 s, 1 s^{2} 3 p, 1 s^{2} 3 d$. Correlation: $1 s^{2} 4 s, 1 s^{2} 4 p, 1 s^{2} 4 d, 1 s^{2} 4 f, 1 s 2 s^{2}, 1 s 2 p^{2}, 1 s 3 s^{2}, 1 s 3 p^{2}, 1 s 3 d^{2}, 1 s 2 s 2 p, 1 s 2 s 3 s$, $1 s 2 s 3 p, 1 s 2 s 3 d, 1 s 2 p 3 s, 1 s 2 p 3 d$. Scaling parameter, $\lambda: 1.30117(1 s)$, 0.99782(2s), 0.87558(2p), 0.98747(3s), 0.86738(3p), 0.80564(3d), 0.98598(4s), $0.86603(4 p), 0.79571(4 d), 0.77675(4 f)$.

C v.-Spectroscopic: $1 s^{2}, 1 s 2 s, 1 s 2 p, 1 s 3 s, 1 s 3 p, 1 s 3 d$. Correlation: $2 s^{2}$, $2 p^{2}, 3 s^{2}, 3 p^{2}, 3 d^{2}, 2 s 2 p, 2 s 3 s, 2 s 3 p, 2 s 3 d, 2 s 4 s, 2 s 4 p, 2 p 3 s, 2 p 3 p, 2 p 3 d, 2 p 4 s$, $2 p 4 p$. Scaling parameter, $\lambda$ : 0.991(1s), 0.991(2s), 0.776(2p), 1.16883(3s), $0.91077(3 p), 1.00746(3 d),-1.59699(4 s),-1.61237(4 p)$.

C vi.-Spectroscopic: $1 s, 2 s, 2 p, 3 s, 3 p, 3 d$. Correlation: $4 s, 4 p, 4 d, 4 f$. Scaling parameter, $\lambda: 1.0(1 s), 1.0(2 s), 1.0(2 p), 1.0(3 s), 1.0(3 p), 1.0(3 d), 1.0(4 s)$, $1.0(4 p), 1.0(4 d), 1.0(4 f)$.

target states for the carbon and nitrogen ions in the close coupling (CC) expansions. Also given are the spectroscopic and correlation electronic configurations and the scaling parameters, $\lambda$, for the Thomas-Fermi-Dirac potential for each orbital. The tables also list the size of the CC expansions in the earlier OP works, showing that present work employs larger expansions for most of the ions. This means that present wave functions are better represented since the correlations due to coupling of more target channels are included.

The total cross section of a given state corresponds to the sum of the partial photoionization cross sections into the ground state as well as the excited states of the residual core ion. While OP work obtained only the total cross sections, we calculate both, the total cross section and the partial cross section for photoionization into the ground state of the core ion. Also, a larger number of bound states of each ion are obtained than the OP data, with $n \leq 10$ (or 11 in some cases) and $0 \leq \ell \leq(n-1)$. In the OP work for total photoionization cross sections of carbon ions, a 10 state expansion for C I (Luo \& Pradhan 1989), six-state expan- 
TABLE 2

TARget TERMS FOR THE EIGENFUNCTION EXPANSIONS OF NITROGEN IONS

\begin{tabular}{|c|c|c|c|c|c|c|c|c|c|c|c|}
\hline \multicolumn{2}{|c|}{$\begin{array}{l}\mathrm{N}_{\text {II }} \\
(1)\end{array}$} & \multicolumn{2}{|c|}{$\begin{array}{l}\mathrm{N} \text { III } \\
(2)\end{array}$} & \multicolumn{2}{|c|}{$\begin{array}{l}\mathrm{N} \text { IV } \\
(3)\end{array}$} & \multicolumn{2}{|c|}{$\begin{array}{l}\mathrm{N} \mathrm{v} \\
(4)\end{array}$} & \multicolumn{2}{|c|}{$\begin{array}{l}\text { N VI } \\
(5)\end{array}$} & \multicolumn{2}{|c|}{$\begin{array}{l}\text { N VII } \\
(6)\end{array}$} \\
\hline $2 s^{2} 2 p^{2}$ & ${ }^{3} P$ & $2 s^{2} 2 p$ & ${ }^{2} P^{o}$ & $2 s^{2}$ & ${ }^{1} S$ & $1 s^{2} 2 s$ & ${ }^{2} S$ & $1 s^{2}$ & ${ }^{1} S$ & $1 s$ & ${ }^{2} S$ \\
\hline $2 s^{2} 2 p^{2}$ & ${ }^{1} D$ & $2 s 2 p^{2}$ & ${ }^{4} P$ & $2 s 2 p$ & ${ }^{3} P^{o}$ & $1 s^{2} 2 p$ & ${ }^{2} P^{o}$ & $1 s 2 s$ & ${ }^{3} S$ & $2 s$ & ${ }^{2} S$ \\
\hline $2 s^{2} 2 p^{2}$ & ${ }^{1} S$ & $2 s 2 p^{2}$ & ${ }^{2} D$ & $2 s 2 p$ & ${ }^{1} P^{o}$ & $1 s^{2} 3 s$ & ${ }^{2} S$ & $1 s 2 p$ & ${ }^{3} P^{o}$ & $2 p$ & ${ }^{2} P^{o}$ \\
\hline $2 s 2 p^{3}$ & ${ }^{5} S^{o}$ & $2 s 2 p^{2}$ & ${ }^{2} S$ & $2 p^{2}$ & ${ }^{3} P$ & $1 s^{2} 3 p$ & ${ }^{2} P^{o}$ & $1 s 2 s$ & ${ }^{1} S$ & $3 s$ & ${ }^{2} S$ \\
\hline $2 s 2 p^{3}$ & ${ }^{3} D^{o}$ & $2 s 2 p^{2}$ & ${ }^{2} P$ & $2 p^{2}$ & ${ }^{1} D$ & $1 s^{2} 3 d$ & ${ }^{2} D$ & $1 s 2 p$ & ${ }^{1} P^{o}$ & $3 p$ & ${ }^{2} P^{o}$ \\
\hline $2 s 2 p^{3}$ & ${ }^{3} P^{o}$ & $2 p^{3}$ & ${ }^{4} S^{o}$ & $2 p^{2}$ & ${ }^{1} S$ & $1 s^{2} 4 s$ & ${ }^{2} S$ & $1 s 3 s$ & ${ }^{3} S$ & $3 d$ & ${ }^{2} D$ \\
\hline $2 s 2 p^{3}$ & ${ }^{1} D^{o}$ & $2 p^{3}$ & ${ }^{2} D^{o}$ & $2 s 3 s$ & ${ }^{3} S$ & $1 s^{2} 4 p$ & ${ }^{2} P^{o}$ & $1 s 3 s$ & ${ }^{1} S$ & $4 f$ & ${ }^{2} F^{o}$ \\
\hline $2 s^{2} 2 p 3 s$ & ${ }^{3} P^{o}$ & $2 p^{3}$ & ${ }^{2} P^{o}$ & $2 s 3 s$ & ${ }^{1} S$ & $1 s^{2} 4 d$ & ${ }^{2} D$ & $1 s 3 p$ & ${ }^{3} P^{o}$ & $4 d$ & ${ }^{2} D$ \\
\hline $2 s^{2} 2 p 3 s$ & ${ }^{1} P^{o}$ & $\ldots$ & $\ldots$ & $2 s 3 p$ & ${ }^{1} P^{o}$ & $1 s^{2} 4 f$ & ${ }^{2} F^{o}$ & $1 s 3 d$ & ${ }^{3} D$ & $4 p$ & ${ }^{2} P^{o}$ \\
\hline $2 s 2 p^{3}$ & ${ }^{3} S^{o}$ & $\ldots$ & $\ldots$ & $2 s 3 p$ & ${ }^{3} P^{o}$ & 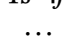 & $\ldots$ & $1 s 3 d$ & ${ }^{1} D$ & $4 s$ & ${ }^{2} S$ \\
\hline$\cdots$ & $\cdots$ & $\ldots$ & $\ldots$ & $2 s 3 d$ & ${ }^{3} D$ & $\ldots$ & $\ldots$ & $1 s 3 p$ & ${ }^{1} P^{o}$ & $\cdots$ & $\ldots$ \\
\hline$\ldots$ & $\ldots$ & & $\ldots$ & $2 s 3 d$ & ${ }^{1} D$ & . & & \multirow{2}{*}{\multicolumn{2}{|c|}{${ }_{11-C C}{ }^{\cdots}$}} & & \\
\hline \multicolumn{2}{|c|}{$10-\mathrm{CC}$} & \multicolumn{2}{|c|}{$8-\mathrm{CC}$} & \multicolumn{2}{|c|}{ 12-CC } & \multicolumn{2}{|c|}{ 9-CC } & & & \multicolumn{2}{|c|}{$10-\mathrm{CC}$} \\
\hline \multicolumn{2}{|c|}{ OP: 12-CC } & \multicolumn{2}{|c|}{ 8-CC } & \multicolumn{2}{|c|}{ 6-CC } & \multicolumn{2}{|c|}{$5-\mathrm{CC}$} & \multicolumn{2}{|c|}{$2-\mathrm{CC}$} & \multicolumn{2}{|c|}{$5-\mathrm{CC}$} \\
\hline \multicolumn{2}{|c|}{$\begin{array}{c}N_{\text {bnd }}=259 \\
E_{g}=2 s^{2} 2 p^{3}\left({ }^{4} S^{o}\right)\end{array}$} & \multicolumn{2}{|c|}{$\begin{array}{c}255 \\
2 s^{2} 2 p^{2}\left({ }^{3} P\right)\end{array}$} & \multicolumn{2}{|c|}{$\begin{array}{c}68 \\
2 s^{2} 2 p\left({ }^{2} P^{o}\right)\end{array}$} & \multicolumn{2}{|c|}{$\begin{array}{c}141 \\
2 s^{2}\left({ }^{1} S\right)\end{array}$} & \multicolumn{2}{|c|}{$\begin{array}{c}54 \\
1 s^{2} 2 s\left({ }^{2} S\right)\end{array}$} & \multicolumn{2}{|c|}{$\begin{array}{c}107 \\
1 s^{2}\left({ }^{1} S\right)\end{array}$} \\
\hline
\end{tabular}

NoTE.-Target terms for the eigenfunction expansions of nitrogen ions: the spectroscopic and correlation configurations, and the values of $\lambda$ parameter are given below. For each ion, $E_{g}$ is the ground state, and $N_{\text {bnd }}$ is the total number of calculated bound states that couple to the target ground state.

N II.-Spectroscopic: $2 s^{2} 2 p^{2}, 2 s 2 p^{3}, 2 s^{2} 2 p 3 s$. Correlation: $2 p^{4}, 2 s^{2} 3 s^{2}, 2 s^{2} 3 p^{2}, 2 s^{2} 3 d^{2}, 2 s^{2} 4 s^{2}, 2 s^{2} 4 p^{2}$, $2 s^{2} 2 p 3 p, 2 s^{2} 2 p 3 d, 2 s^{2} 2 p 4 s, 2 s 2 p^{2} 3 s, 2 s 2 p^{2} 3 p, 2 s 2 p^{2} 3 d, 2 s^{2} 3 s 3 p, 2 s^{2} 3 p 3 d, 2 s^{2} 3 s 4 s, 2 s^{2} 2 p 4 p, 2 p^{3} 3 s, 2 p^{3} 3 p, 2 p^{3} 3 d$. Scaling parameter, $\lambda$ : 1.47637(1s), 1.27184(2s), 1.19306(2p), 1.22385(3s), 1.32(3p), $-0.96476(3 d),-0.74971(4 s)$, $-0.79911(4 p)$.

N III.-Spectroscopic: $2 s^{2} 2 p, 2 s 2 p^{2}, 2 p^{3}$. Correlation: $2 s^{2} 3 s, 2 s^{2} 3 p, 2 s^{2} 3 d, 2 s 2 p 3 s, 2 s 2 p 3 p, 2 s 2 p 3 d, 2 s 3 d^{2}$, $2 s 2 p 3 d, 2 p^{2} 3 s, 2 p^{2} 3 p, 2 p^{2} 3 d$. Scaling parameter, $\lambda: 1.41146(1 s), 1.87569(2 s), 1.71613(2 p),-1.13364(3 s)$, $-1.08962(3 p),-1.10297(3 d)$.

N IV.-Spectroscopic: $1 s^{2} 2 s^{2}, 1 s^{2} 2 s 2 p, 1 s^{2} 2 p^{2}, 1 s^{2} 2 s 3 s, 1 s^{2} 2 s 3 p, 1 s^{2} 2 s 3 d$. Correlation: $1 s^{2} 2 p 3 s, 1 s^{2} 2 s 4 s$, $1 s^{2} 2 s 4 p, 1 s^{2} 2 p 3 p$. Scaling parameter, $\lambda: 1.4(1 s), 1.4(2 s), 1.127(2 p), 1.2(3 s), 1.1(3 p), 1.1(3 d), 10.6115(4 s)$, 4.37106(4p), 4.1(4d).

$\mathrm{N} v$.- Spectroscopic: $1 s^{2} 2 s, 1 s^{2} 2 p, 1 s^{2} 3 s, 1 s^{2} 3 p, 1 s^{2} 3 d$. Correlation: $1 s^{2} 4 s, 1 s^{2} 4 p, 1 s^{2} 4 d, 1 s^{2} 4 f, 1 s 2 s^{2}, 1 s 2 p^{2}$, $1 s 3 s^{2}, 1 s 3 p^{2}, 1 s 3 d^{2}, 1 s 2 s 2 p, 1 s 2 s 3 s, 1 s 2 s 3 p, 1 s 2 s 3 d, 1 s 2 p 3 s, 1 s 2 p 3 d$. Scaling parameter, $\lambda: 1.30117(1 s)$, $0.99782(2 s), \quad 0.87558(2 p), \quad 0.98747(3 s), \quad 0.86738(3 p), \quad 0.80564(3 d), 0.98598(4 s), \quad 0.86603(4 p), 0.79571(4 d)$, $0.77675(4 f)$.

N vi.-Spectroscopic: $1 s^{2}, 1 s 2 s, 1 s 2 p, 1 s 3 s, 1 s 3 p, 1 s 3 d$. Correlation: $2 s^{2}, 2 p^{2}, 3 s^{2}, 3 p^{2}, 3 d^{2}, 2 s 2 p, 2 s 3 s, 2 s 3 p$, $2 s 3 d, 2 s 4 s, 2 s 4 p, 2 p 3 s, 2 p 3 p, 2 p 3 d, 2 p 4 s, 2 p 4 p$. Scaling parameter, $\lambda: 0.991(1 s), 0.991(2 s), 0.776(2 p), 1.16883(3 s)$, $0.91077(3 p), 1.00746(3 d),-1.59699(4 s),-1.61237(4 p)$.

$\mathrm{N}$ vII.-Spectroscopic: $1 s, 2 s, 2 p, 3 s, 3 p, 3 d$. Correlation: $4 s, 4 p, 4 d, 4 f$. Scaling parameter, $\lambda: 1.0(1 s), 1.0(2 s)$, $1.0(2 p), 1.0(3 s), 1.0(3 p), 1.0(3 d), 1.0(4 s), 1.0(4 p), 1.0(4 d), 1.0(4 f)$.

sion for C II (Fernley et al. 1996, hereafter F1), five-state expansion for C III (Tully, Seaton, \& Berrington 1990), twostate expansion for C IV (Peach, Saraph, \& Seaton 1988), and five-state expansion for C v (Fernley et al. 1987, hereafter F2) were employed. As mentioned above, we employ a larger expansion for each carbon ion, except $\mathrm{C}$ I, for which we also use a 10 state expansion (Nahar \& Pradhan 1991).

The total photoionization cross sections of the nitrogen ions for the OP work were obtained using a 12 state eigenfunction expansion for N I (Burke \& Lennon 1996), eightstate eigenfunction for N II (Luo \& Pradhan 1989), six-state eigenfunction for $\mathrm{N}$ III (F1), five-state eigenfunction for $\mathrm{N}$ IV (Tully et al. 1990), two-state eigenfunction for $\mathrm{N} \mathrm{v}$ (Peach et al. 1988), and five-state eigenfunction for N VI (F2). As for the carbon ions, present results represent correlation effects better for N III-N vi. For N II, we also use an eight- state expansion (Nahar \& Pradhan 1991). For N I, we use a 10 state expansion, but the expansion includes the two lowlying states of $2 s^{2} 2 p 3 s$, which were not included by Burke \& Lennon (1996).

The photoionization cross sections for the hydrogen-like ions $\mathrm{C}$ VI and $\mathrm{N}$ VII are obtained in the hydrogenic approximation using a procedure developed by Storey \& Hummer (1992). Similar data are available through TOPbase (Cunto et al. 1993) obtained by Seaton (1996).

We resolve the Rydberg series of autoionizing resonances in the photoionization cross sections of the ions in detail. The resonance profiles decrease in width with their effective quantum number as $v^{-3}$, relative to the threshold of convergence such that $v(E)=z /\left[\left(E-E_{t}\right)\right]^{1 / 2}$ (in rydbergs), where $E_{t}$ is the target threshold energy and $E$ is the continuum electron energy (note that the letter $v$ is also used to denote the photon frequency). We resolve the structures with $\Delta v=0.01$ up to effective quantum number, $v=10.0$, i.e., at 100 energies for each interval $(v, v+1)$. Furthermore, the near-threshold resonances that contribute predominantly to low-temperature recombination are resolved on a much finer energy mesh with typically 2000 energies just above the ionization threshold.

\subsection{Total and State-specific Recombination Rate Coefficients}

Recombination into bound states of the electron-ion system is divided into two groups according to $n S L \pi$ with (A) low- $n$ states, $n \leq n_{o}$, and (B) high- $n$ states, $n_{o}<n<\infty$. The $S, L$, and $\pi$ refer to the total spin, orbital angular momentum, and parity of the state(s).

For electron-ion recombination to the low- $n$ bound states of group A, the recombination cross sections, $\sigma_{\mathrm{RC}}$, and the rate coefficients, $\alpha_{R}$, are obtained from the detailed partial photoionization cross sections, $\sigma_{\mathrm{PI}}(g)$, through the Milne relation. Recombination rate coefficients of individ- 
TABLE 3

COMPARISON OF DR AND EXCITATION COLlision STRENGTHS

\begin{tabular}{|c|c|c|c|c|c|c|c|c|c|}
\hline \multirow{2}{*}{\multicolumn{2}{|c|}{ Target State }} & \multirow[b]{2}{*}{$\langle\Omega(\mathrm{DR})\rangle$} & \multicolumn{2}{|c|}{$\Omega(\mathrm{EIE})$} & \multirow{2}{*}{\multicolumn{2}{|c|}{ Target State }} & \multirow[b]{2}{*}{$\langle\Omega(\mathrm{DR})\rangle$} & \multicolumn{2}{|c|}{$\Omega(\mathrm{EIE})$} \\
\hline & & & ipert $=0$ & ipert $=1$ & & & & ipert $=0$ & ipert $=1$ \\
\hline \multicolumn{10}{|c|}{$\mathrm{C}_{\text {I }}\left(\mathrm{C}\right.$ II: $\left.2 s^{2} 2 p^{2} P^{o}\right)$} \\
\hline $2 s 2 p^{2}$ & ${ }^{2} D$ & 6.03 & 5.93 & 5.72 & $2 s 2 p^{2}$ & ${ }^{2} S$ & 2.93 & 2.93 & 3.06 \\
\hline $2 s 2 p^{2}$ & ${ }^{2} P$ & 4.89 & 5.44 & 5.44 & $2 s^{2} 3 s$ & ${ }^{2} S$ & 0.850 & 0.850 & 0.607 \\
\hline \multicolumn{10}{|c|}{$\mathrm{C}$ II $\left(\mathrm{C}\right.$ III: $\left.2 s^{2}{ }^{1} S\right)$} \\
\hline $2 s 2 p$ & ${ }^{1} P^{o}$ & 3.15 & 3.15 & 3.34 & $2 s 3 p$ & ${ }^{1} P^{o}$ & 0.099 & 0.092 & 0.085 \\
\hline \multicolumn{10}{|c|}{$\mathrm{C}$ III $\left(\mathrm{C}\right.$ IV: $\left.1 s^{2} 2 s^{2} S\right)$} \\
\hline $2 p$ & ${ }^{2} P^{o}$ & 8.71 & 8.66 & 8.50 & $3 p$ & ${ }^{2} P^{o}$ & 0.483 & 0.533 & 0.533 \\
\hline $4 p$ & ${ }^{2} P^{o}$ & 0.118 & 0.186 & 0.186 & $\ldots$ & $\ldots$ & $\ldots$ & $\ldots$ & $\ldots$ \\
\hline \multicolumn{10}{|c|}{$\mathrm{C}$ IV $\left(\mathrm{C} \mathrm{v}: 1 s^{2}{ }^{1} S\right)$} \\
\hline $1 s 2 p$ & ${ }^{1} P^{o}$ & 0.028 & 0.028 & 0.028 & $1 s 3 p$ & ${ }^{1} P^{o}$ & 0.0079 & 0.0079 & 0.0073 \\
\hline \multicolumn{10}{|c|}{$\mathrm{C} \mathrm{v}\left(\mathrm{C}\right.$ vI: $\left.1 s^{2} S\right)$} \\
\hline $2 p$ & ${ }^{2} P^{o}$ & 0.100 & 0.099 & 0.098 & $3 p$ & ${ }^{2} P^{o}$ & 0.018 & 0.018 & 0.018 \\
\hline $4 p$ & ${ }^{2} P^{o}$ & 0.0062 & 0.0056 & 0.0050 & $\ldots$ & $\ldots$ & $\ldots$ & $\ldots$ & $\ldots$ \\
\hline \multicolumn{10}{|c|}{$\mathrm{N}$ I $\left(\mathrm{N}\right.$ II: $\left.2 p^{2}{ }^{3} P\right)$} \\
\hline $2 s 2 p^{3}$ & ${ }^{3} D^{o}$ & 3.56 & 3.56 & 3.44 & $2 s 2 p^{3}$ & ${ }^{3} P^{o}$ & 2.66 & 2.66 & 2.72 \\
\hline $2 p 3 s$ & ${ }^{3} P^{o}$ & 0.871 & 0.901 & 0.909 & $2 s 2 p^{3}$ & ${ }^{3} S^{o}$ & 1.38 & 1.38 & 1.34 \\
\hline \multicolumn{10}{|c|}{$\mathrm{N}$ II (N III: $\left.2 s^{2} 2 p^{2} P^{o}\right)$} \\
\hline $2 s 2 p^{2}$ & ${ }^{2} D$ & 5.11 & 5.09 & 5.83 & $2 s 2 p^{2}$ & ${ }^{2} S$ & 2.07 & 2.07 & 2.01 \\
\hline $2 s 2 p^{2}$ & ${ }^{2} P$ & 9.35 & 9.29 & 8.84 & $\ldots$ & $\ldots$ & $\ldots$ & $\ldots$ & $\ldots$ \\
\hline \multicolumn{10}{|c|}{$\mathrm{N}$ III $\left(\mathrm{N}\right.$ IV $\left.: 2 s^{2}{ }^{1} S\right)$} \\
\hline $2 s 2 p$ & ${ }^{1} P^{o}$ & 2.95 & 2.95 & 2.95 & $2 s 3 p$ & ${ }^{1} P^{o}$ & 0.051 & 0.051 & 0.047 \\
\hline \multicolumn{10}{|c|}{$\mathrm{N}$ IV $\left(\mathrm{N}\right.$ v: $\left.1 s^{2} 2 s^{2} S\right)$} \\
\hline $2 p$ & ${ }^{2} P^{o}$ & 6.95 & 6.99 & 6.42 & $3 p$ & ${ }^{2} P^{o}$ & 0.181 & 0.173 & 0.173 \\
\hline $4 p$ & ${ }^{2} P^{o}$ & 0.088 & 0.066 & 0.083 & $\cdots$ & $\cdots$ & $\cdots$ & $\ldots$ & $\cdots$ \\
\hline \multicolumn{10}{|c|}{$\mathrm{N}$ v (N vI: $\left.1 s^{2}{ }^{1} S\right)$} \\
\hline $2 p$ & ${ }^{1} P^{o}$ & 0.0228 & 0.0228 & 0.0228 & $3 p$ & ${ }^{1} P^{o}$ & 0.0058 & 0.0058 & 0.056 \\
\hline \multicolumn{10}{|c|}{$\mathrm{N}$ VI $\left(\mathrm{N}\right.$ VII: $\left.1 s^{2} S\right)$} \\
\hline $2 p$ & ${ }^{2} P^{o}$ & 0.055 & 0.054 & 0.054 & $3 p$ & ${ }^{2} P^{o}$ & 0.013 & 0.012 & 0.011 \\
\hline $4 p$ & ${ }^{2} P^{o}$ & 0.0018 & 0.0015 & 0.0020 & $\ldots$ & $\ldots$ & $\ldots$ & $\ldots$ & $\ldots$ \\
\hline
\end{tabular}

NoTE.-Comparison of DR collision strength, $\langle\Omega(D R)\rangle$, and excitation collision strength, $\Omega(\mathrm{EIE})$, at the thresholds for dipole allowed transitions from the ground state in the target. The target ground state is within the parentheses.

ual states are then obtained by averaging the recombination cross sections over the Maxwellian electron distribution at a given temperature (NP). The sum of these individual rates provides the contributions of the low- $n$ bound states to the total recombination rates, i.e.,

$$
\begin{aligned}
\alpha_{R}\left(T ; n \leq n_{0}\right)= & \sum_{j}^{N_{\text {bnd }}} \frac{g_{i}}{g_{j}} \frac{2}{k T c^{2} \sqrt{2 \pi m_{e}^{3} k T}} \\
& \times \int_{0}^{\infty} E^{2} \sigma_{\mathrm{PI}}(g, j, \epsilon) e^{-\epsilon / k T} d \epsilon
\end{aligned}
$$

(NP), where $E=h v=\epsilon+I_{P}, \epsilon$ is the photoelectron energy, $I_{P}$ is the ionization potential, $g_{i}$ and $g_{j}$ are the statistical weight factors of the recombining and recombined ions, respectively, and the sum is over partial recombination rates of bound states $j$ extending over the total number of bound states $N_{\text {bnd }}$. As the cross sections include the detailed structures of autoionizing resonances, the total corresponds to the inclusion of RR and DR in a unified and ab initio manner for recombination to low- $n$ states. A new program RECOMB is employed for these computations.

For the group B states $\left(n_{0}<n \leq \infty\right)$, in which recombination is dominated by DR, the theory of DR developed by Bell \& Seaton (1985; see also Nahar \& Pradhan 1994; Nahar 1996b) is applied to compute the DR rate coefficients. The collision strengths for DR, $\Omega(\mathrm{DR})$, are obtained in the close coupling (CC) approximation using the same eigenfunction expansions that are used for the photoionization cross sections. An extension of the asymptotic wave function code, STGF, from the $\boldsymbol{R}$-matrix package of codes is used for the DR calculations (the extended code is named STGFDR). The transition probabilities for the dipole allowed transitions in the target ions are obtained from the oscillator strengths calculated with the same CC expansions. The convergence of the $\boldsymbol{R}$-matrix basis set, consistent with the $\boldsymbol{R}$-matrix boundary, was checked by calculating the electron impact excitation (EIE) collision strengths, 
$\Omega(E I E)$, independently at the threshold energies, with (ipert $=1$ ) and without (ipert $=0$ ) the inclusion of perturbative multipole potential contributions in the asymptotic part of the wave functions (Nahar \& Pradhan 1994; ipert is the switching parameter in the code to turn on or off the multipole potential contributions). These values are given in Table 3 showing nearly complete agreement between the two sets of $\Omega$ (EIE) values. The convergence of the CC expansions is also checked with respect to the partial wave contributions to $\Omega$ (EIE).

The contributions from the high- $n$ states to the total $\alpha_{R}$ are obtained from the resonance averaged collision strength, $\langle\Omega(\mathrm{DR})\rangle$, although we calculate both the detailed and resonance averaged forms of the collision strength. The "background" recombination (RR-type) for the high- $n$ states $(11<n \leq \infty)$ is negligibly small, except at very low temperatures. However, we include it in the total recombination rate coefficients at all temperatures in the hydrogenic approximation and refer to it as "top-up" (Nahar 1996b). The rapid rise in $\alpha_{R}$ toward very low temperatures is due to low-energy recombination to the infinite number of these high- $n$ states.

\section{RESULTS AND DISCUSSION}

\subsection{Total and Partial Photoionization Cross Sections}

The total photoionization cross sections for ionization

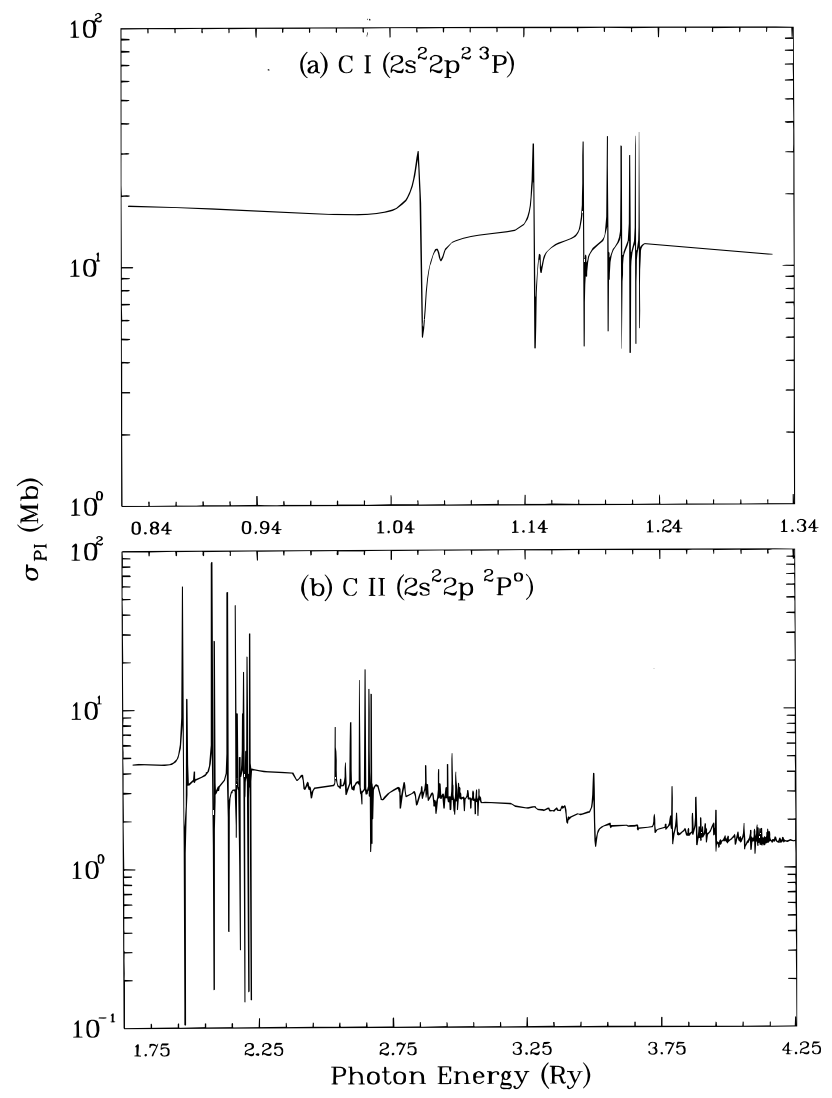

into the ground and the excited states of the core ion have been calculated for a large number of bound states. The ground state total photoionization cross sections of $\mathrm{C} \mathrm{I}-\mathrm{C} \mathrm{V}$ are shown in Figures $1 a-1 e$ and for $\mathrm{N} \mathrm{I-N} \mathrm{VI} \mathrm{in} \mathrm{Figures}$ $2 a-2 f$. The total photoionization cross sections of $\mathrm{C}$ I, N II (Nahar \& Pradhan 1991), and C II (Nahar \& Pradhan 1994) are as obtained earlier by the authors in the cited papers. As the present work includes larger CC expansions for most of the ions than in the OP work, more resonance structures result from the Rydberg series of autoionizing states belonging to the target states as well as from the photoexcitation of core (PEC) or target states (e.g., Nahar \& Pradhan 1994). The resonances as well as some resultant background enhancement in the photoionization cross sections, $\sigma_{\mathrm{PI}}$, can be seen in Figures 1 and 2.

Figure 3 presents a comparison of the total photoionization cross sections of the ground ${ }^{4} S^{o}$ state of $\mathrm{N}$ I, with the experimentally measured values of Samson \& Angel (1990) and with the OP cross sections of Burke \& Lennon (1996). The first detailed work on the photoionization cross sections of the ground state of N I was carried out by Le Dourneuf, Lan, \& Zeippen (1976, 1979; not shown here, as these are close to those of Burke \& Lennon 1996). The agreement with the experimental values (Samson \& Angel 1990 ) is within $15 \%$ or better in most of the energy range shown, as well as for the detailed resonance structures (possibly within experimental uncertainties).
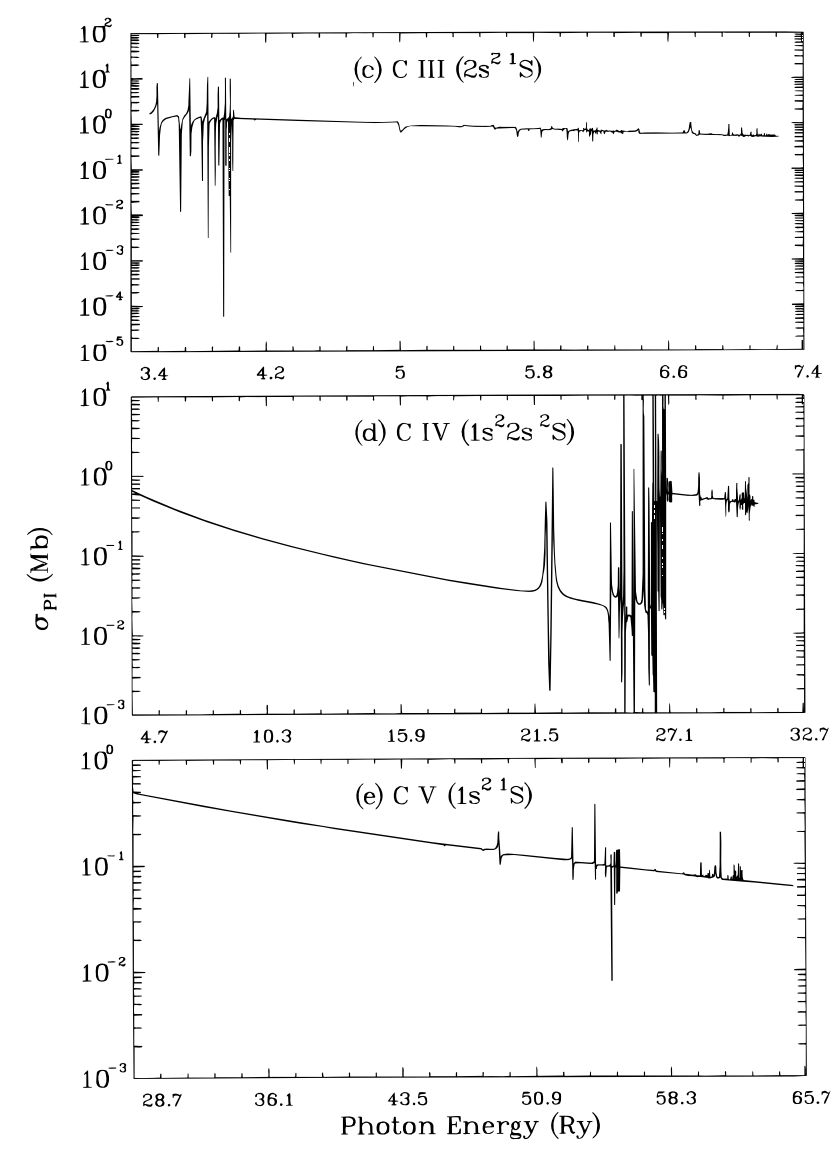

FIG. 1.-Total photoionization cross sections of the ground states of carbon ions: $(a){ }^{3} P$ state of $\mathrm{C}$ I, $(b){ }^{2} P^{o}$ state of C II, $(c){ }^{1} S$ state of C III, $(d){ }^{2} S$ state of $\mathrm{C}$ IV, and $(e)^{1} S$ state of $\mathrm{C} \mathrm{v}$. 

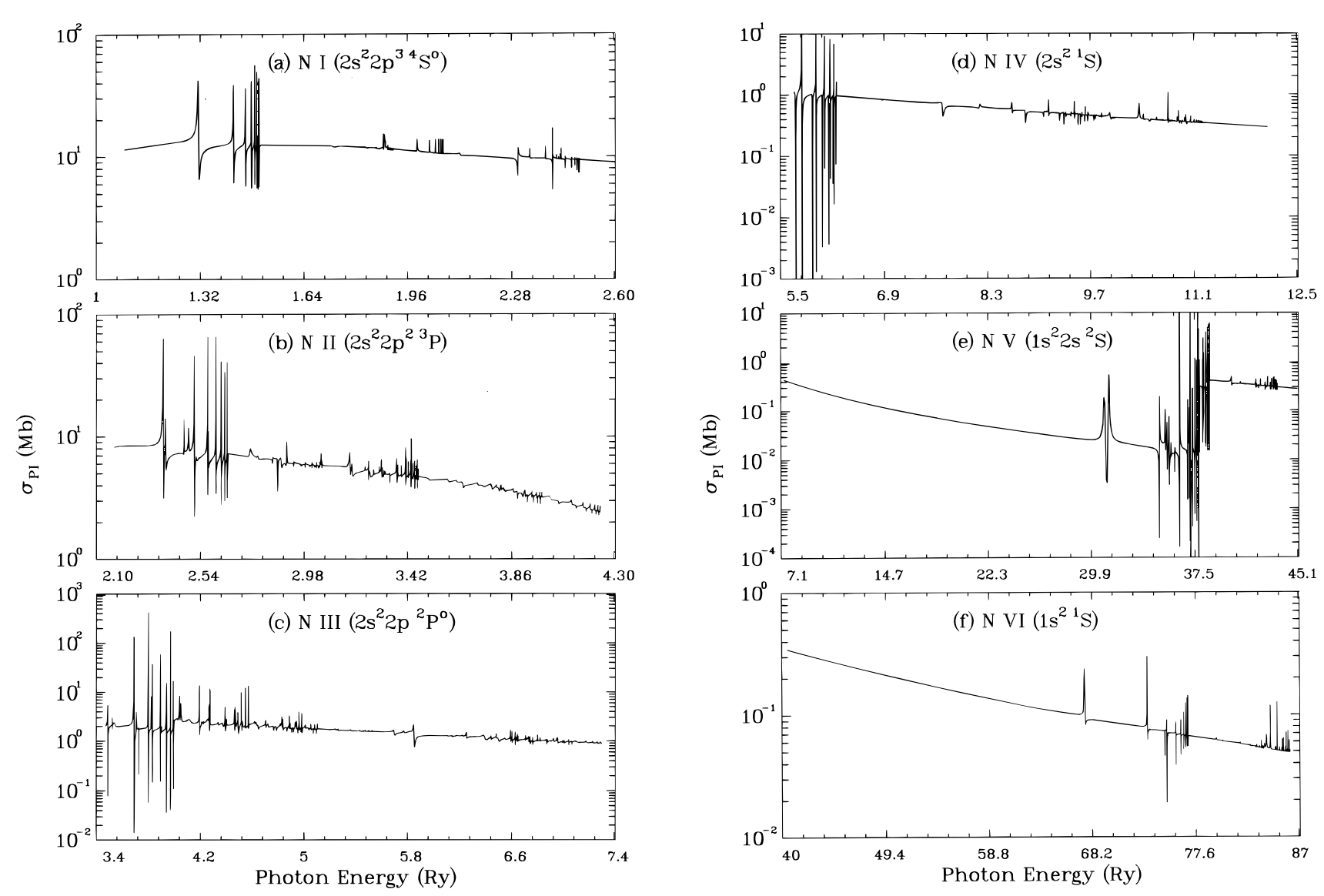

Fig. 2.-Total photoionization cross sections of the ground states of nitrogen ions: $(a){ }^{4} S^{o}$ state of N I, $(b){ }^{3} P$ state of N II, $(c){ }^{2} P^{o}$ state of N III, $(d){ }^{1} S$ state of $\mathrm{N}$ IV, $(e){ }^{2} S$ state of $\mathrm{N} \mathrm{v}$, and $(f){ }^{1} S$ state of N VI.

We calculate the partial photoionization cross sections, $\sigma_{\mathrm{PI}}(g)$, for photoionization into the ground state of the residual ion, as they are needed for the calculations of the recombination rate coefficients, $\alpha_{R}$. The total number of calculated bound states, $N_{\text {bnd }}$, that couple to the core ground state and for which partial cross sections are obtained are listed in Table 1. The number of bound states

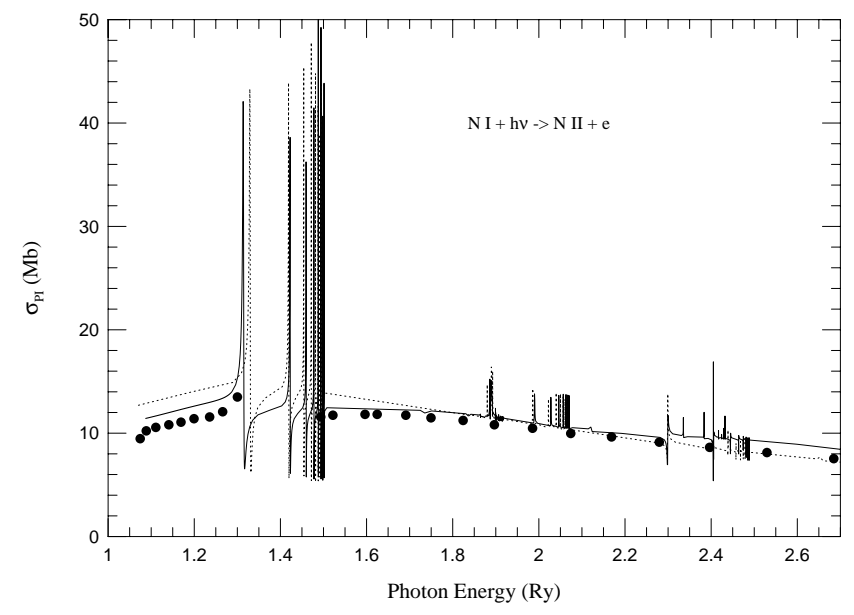

Fig. 3.-Comparison of the present total photoionization cross sections (solid line) for the ground state of $\mathrm{N} \mathrm{I}^{4}{ }^{4} S^{o}$, with the OP cross sections (dotted line) and the experimental values of Samson \& Angel (1990; filled circles).

obtained in this work is larger than in the OP data (as in TOPbase) because of consideration of more target states and partial waves. The partial photoionization cross sections for a few ions, $\mathrm{C}_{\mathrm{I}}, \mathrm{C}$ II, and $\mathrm{N}$ II, have been reported earlier (Nahar 1995, 1996a).

We examine in some detail the structures of $\sigma_{\mathrm{PI}}(g)$ for a number of excited states of both carbon and nitrogen ions that affect the recombination rate coefficients. Figure 4 presents $\sigma_{\mathrm{PI}}(g)$ of three excited states of C III that dominate the recombination at different temperatures. $2 s 5 g\left({ }^{3} G\right)$ is a highly excited state; however, its extensive resonance structures (Fig. 4a) at higher energies, with high peak values, contribute significantly in the high-temperature region. The $\sigma_{\mathrm{PI}}(g)$ of state $2 s 2 p\left({ }^{3} P^{o}\right)$ in Figure $4 b$ shows that although there are no prominent autoionizing resonances, its effective background cross section is large and decays slowly with energy. This state is one of the dominant contributors to the recombination rates over a wide temperature range. The state $2 s 2 p\left({ }^{1} P^{o}\right)$ is one of the dominant ones at lower temperatures (up to about $1000 \mathrm{~K}$ ) because of the resonance structures in the near-threshold region (Fig. 4c). Usually the ground state is one of the dominant contributors to the recombination rates, but depending on the temperature, the excited states can be more prominent.

The excited state photoionization cross sections may differ considerably from the simple hydrogenic forms usually assumed. The reason is that in addition to the infinite series of relatively narrow resonances, large resonances may also exist because of the PEC for the excited states. PEC resonances occur close to the energies of dipole transitions in the core ion and are essentially the inverse of the DR process. They manifest themselves strongly in the 

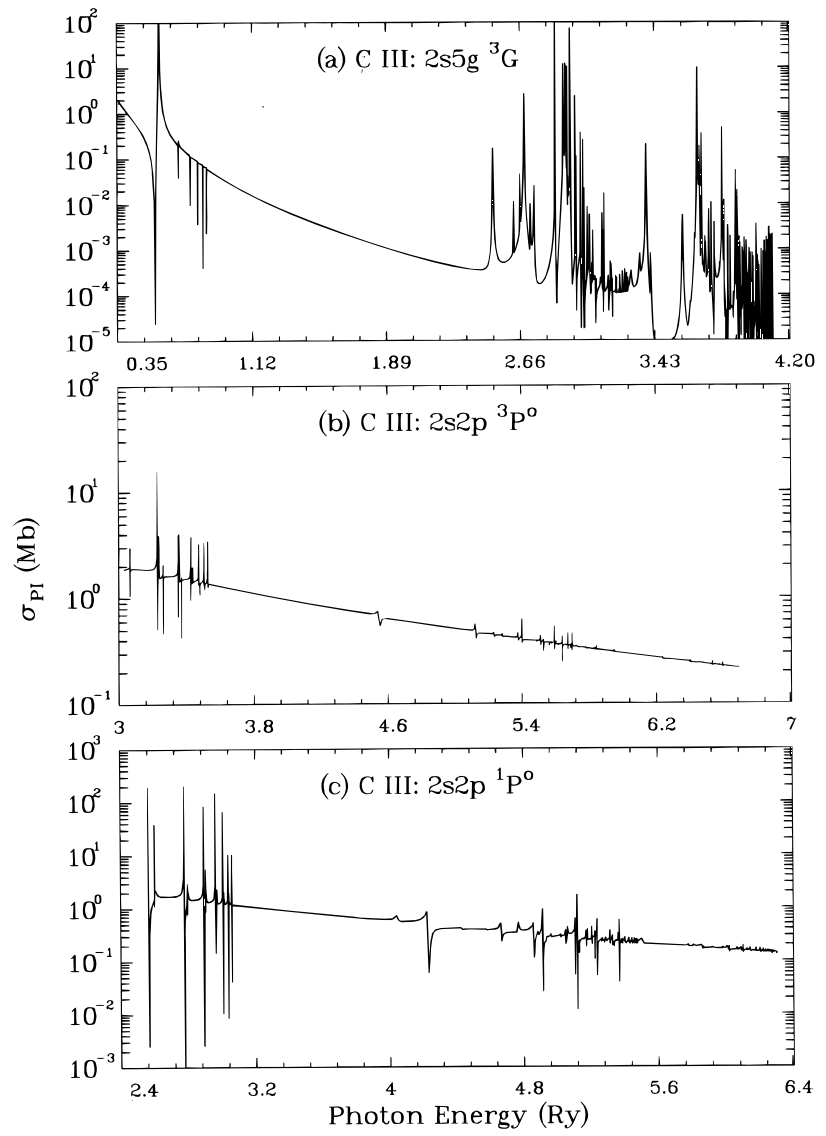

FIG. 4.-Partial photoionization cross sections of the excited states of C III: (a) ${ }^{3} G,(b){ }^{3} P^{o}$, and $(c){ }^{1} P^{o}$, which provide the dominant contributions to the total recombination rate coefficients.

photoionization of excited bound states along a Rydberg series. The outer Rydberg electron remains a "spectator," weakly interacting with the core ion, while the incident photon excites the core. Figure 5 presents the $\sigma_{\mathrm{PI}}(g)$ of six excited states of $\mathrm{N}$ III from the Rydberg series, $2 s^{2} n p\left({ }^{2} P^{o}\right)$, $2 \leq n \leq 8$, including the ground state $2 s^{2} 2 p\left({ }^{2} P^{o}\right)$. The PEC positions (shown by arrows) are at energies corresponding to the dipole transitions from the ground state $1 s^{2} 2 s^{2}\left({ }^{1} S\right)$ of the core ion $\mathrm{N}$ IV, to the two excited odd parity states, $z^{1} P^{o}$ and $y^{1} P^{o}$. The PECs become more distinct with increasing $n$, and may attenuate the background cross section by orders of magnitude at higher energies.

\subsection{State-specific and Total Recombination Rate Coefficients}

Table 4 presents the state-specific, partial recombination rate coefficients of dominant bound states of group A for a few ions, $\mathrm{C}$ III, $\mathrm{N}$ I, and $\mathrm{N}$ III at four temperatures: $\log _{10}$ $T=2.0,3.0,3.7$, and 4.0. (State-specific rate coefficients for all ions are available electronically.) These are listed in order of their percentage contributions to the total $\alpha_{R}(T)$ at these temperatures. Their sums show that a limited number of states usually dominate the recombination rates. Also, the number, the order, and the amount of contribution of the individual bound states vary with temperature depending on the positions of autoionizing resonances in the cross sections. The ground state may not necessarily be the dominant contributor at all temperatures. The individual, statespecific, recombination rates of the low- $n$ bound states of

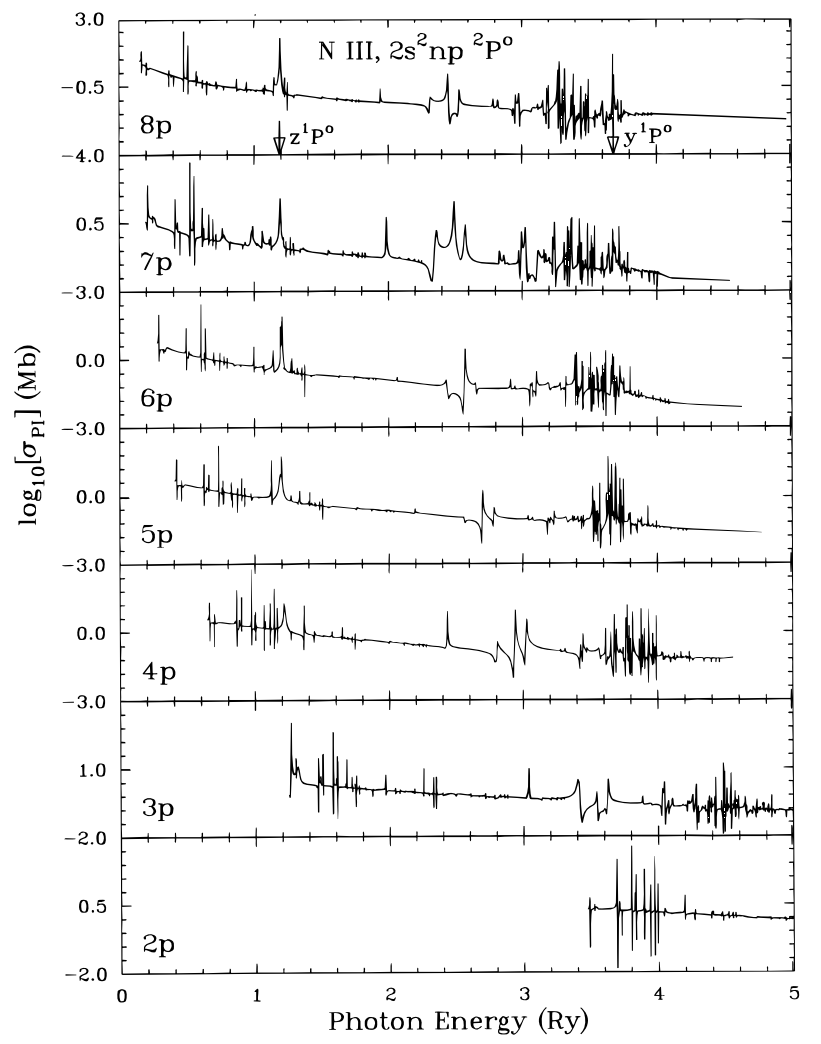

FIG. 5.-Partial photoionization cross sections of the series of Rydberg bound states, $2 s^{2} n p\left({ }^{2} P^{o}\right), 2 \leq n \leq 8$ of $\mathrm{N}$ III, illustrating the photoexcitationof-core (PEC) resonances. The arrows (top) indicate the energies of states for dipole allowed transitions corresponding to the PECs.

group A should be close to their total recombination rate coefficients for $T<10^{4} \mathrm{~K}$. With $k T<1 \mathrm{eV}$, the incident electron energies lie well below the first excited target threshold of the target ions (at higher temperatures the state-specific DR must also be included; this is not considered in the present work). The state-specific rates may also be applicable for calculating the recombination rates for lines, $\alpha_{R}(g, i \rightarrow j)$, a measure of the line intensity for the transition $i \rightarrow j$.

For the high- $n$ contributions to the total recombination rate coefficients, the DR collision strengths, $\Omega(\mathrm{DR})$, are obtained for both cases: (1) delineating the autoionizing resonances in detail, and (2) averaging over the resonances. Figure 6 shows an example of $\Omega(\mathrm{DR})$ for $\left(e^{-}, \mathrm{N}\right.$ II) in the region below the first target threshold, ${ }^{3} D^{o}$, for the dipole allowed transition from the ground state ${ }^{3} P$ : the detailed (dotted line) and the resonance averaged (solid line). A common feature can be observed: as the effective quantum number increases, the DR resonances get narrower and denser, dominating the recombination process as they approach the excited threshold. The pattern is more distinct in the solid line for the resonance-averaged collision strength $\langle\Omega(\mathrm{DR})\rangle$, which starts with a very low value but rises sharply (approximately as $v^{3}$ ) as it peaks at the threshold. The peak values of the $\langle\Omega(D R)\rangle$ at the four excited target thresholds of $\mathrm{N}_{\mathrm{I}}$ for dipole allowed transitions as well as for the other ions are given in Table 3.

The filled circle in Figure 6 corresponds to the value of $\Omega(E I E)$ at the threshold ${ }^{3} D^{o}$. The peak values of $\langle\Omega(D R)\rangle$ at the thresholds are compared with the $\Omega(E I E)$ values (ipert $=0$ ). An important feature of the unified approach is 
TABLE 4

State-SPECIFIC Recombination Rate CoefFicients

\begin{tabular}{|c|c|c|c|c|c|c|c|c|c|c|c|}
\hline \multicolumn{3}{|c|}{$100 \mathrm{~K}$} & \multicolumn{3}{|c|}{$1000 \mathrm{~K}$} & \multicolumn{3}{|c|}{$5012 \mathrm{~K}$} & \multicolumn{3}{|c|}{$10,000 \mathrm{~K}$} \\
\hline State & & $\alpha_{R}$ & State & & $\alpha_{R}$ & State & & $\alpha_{R}$ & State & & $\alpha_{R}$ \\
\hline \multicolumn{12}{|c|}{$\mathrm{C}$ III } \\
\hline $\begin{array}{l}1 s^{2} 2 s^{2} S^{e} 2 p \\
1 s^{2} 2 s^{2} S^{e} 4 p \\
1 s^{2} 2 p^{2} P^{o} 3 p \\
1 s^{2} 2 s^{2} S^{e} 2 p \\
1 s^{2} 2 p^{2} P^{o} 3 d \\
1 s^{2} 2 p^{2} \\
1 s^{2} 2 p^{2} P^{o} 3 d \\
1 s^{2} 2 s^{2} S^{e} 4 d \\
1 s^{2} 2 s^{2} S^{e} 5 f \\
1 s^{2} 2 p^{2} P^{o} 3 s \\
1 s^{2} 2 s^{2} S^{e} 3 p \\
1 s^{2} 2 s^{2} S^{e} 3 d \\
1 s^{2} 2 p^{2} P^{o} 3 d \\
1 s^{2} 2 s^{2} S^{e} 5 p \\
1 s^{2} 2 s^{2} \\
1 s^{2} 2 s^{2} S^{e} 6 p \\
1 s^{2} 2 p^{2} \\
1 s^{2} 2 s^{2} S^{e} 4 f \\
1 s^{2} 2 s^{2} S^{e} 7 p \\
1 s^{2} 2 p^{2} P^{o} 3 p\end{array}$ & $\begin{array}{l}{ }^{1} P^{o} \\
{ }^{1} P^{o} \\
{ }^{3} D^{e} \\
{ }^{3} P^{o} \\
{ }^{1} F^{o} \\
{ }^{1} D^{e} \\
{ }^{3} F^{o} \\
{ }^{3} D^{e} \\
{ }^{1} F^{o} \\
{ }^{1} P^{o} \\
{ }^{3} P^{o} \\
{ }^{3} D^{e} \\
{ }^{1} P^{o} \\
{ }^{1} P^{o} \\
{ }^{1} S^{e} \\
{ }^{1} P^{o} \\
{ }^{3} P^{e} \\
{ }^{3} F^{o} \\
{ }^{1} P^{o} \\
{ }^{1} D^{e}\end{array}$ & $\begin{array}{l}1.54 \mathrm{E}-10 \\
3.23 \mathrm{E}-11 \\
2.36 \mathrm{E}-11 \\
1.01 \mathrm{E}-11 \\
5.54 \mathrm{E}-12 \\
4.67 \mathrm{E}-12 \\
4.62 \mathrm{E}-12 \\
3.78 \mathrm{E}-12 \\
3.00 \mathrm{E}-12 \\
2.81 \mathrm{E}-12 \\
2.33 \mathrm{E}-12 \\
2.28 \mathrm{E}-12 \\
1.67 \mathrm{E}-12 \\
1.41 \mathrm{E}-12 \\
1.37 \mathrm{E}-12 \\
1.27 \mathrm{E}-12 \\
1.14 \mathrm{E}-12 \\
1.04 \mathrm{E}-12 \\
7.14 \mathrm{E}-13 \\
6.85 \mathrm{E}-13\end{array}$ & $\begin{array}{l}1 s^{2} 2 s^{2} S^{e} 2 p \\
1 s^{2} 2 s^{2} S^{e} 2 p \\
1 s^{2} 2 s^{2}{ }^{2} S^{e} 4 p \\
1 s^{2} 2 p^{2} P^{o} 3 d \\
1 s^{2} 2 p{ }^{2} P^{o} 3 p \\
1 s^{2} 2 p^{2} \\
1 s^{2} 2 p^{2} \\
1 s^{2} 2 s^{2} S^{e} 3 d \\
1 s^{2} 2 s^{2} S^{e} 4 d \\
1 s^{2} 2 p^{2} P^{o} 3 d \\
1 s^{2} 2 s^{2} S^{e} 3 p \\
1 s^{2} 2 s^{2} \\
1 s^{2} 2 s^{2} S^{e} 5 f \\
1 s^{2} 2 p^{2} P^{o} 3 s \\
1 s^{2} 2 p^{2} P^{o} 3 p \\
1 s^{2} 2 s^{2} S^{e} 4 f \\
1 s^{2} 2 s^{2} S^{e} 4 p \\
1 s^{2} 2 s^{2} S^{e} 3 p \\
1 s^{2} 2 s^{2} S^{e} 5 d \\
1 s^{2} 2 s^{2} S^{e} 3 s\end{array}$ & $\begin{array}{l}{ }^{1} P^{o} \\
{ }^{3} P^{o} \\
{ }^{1} P^{o} \\
{ }^{3} F^{o} \\
{ }^{3} D^{e} \\
{ }^{1} D^{e} \\
{ }^{3} P^{e} \\
{ }^{3} D^{e} \\
{ }^{3} D^{e} \\
{ }^{1} F^{o} \\
{ }^{3} P^{o} \\
{ }^{1} S^{e} \\
{ }^{1} F^{o} \\
{ }^{1} P^{o} \\
{ }^{1} D^{e} \\
{ }^{3} F^{o} \\
{ }^{3} P^{o} \\
{ }^{1} P^{o} \\
{ }^{3} D^{e} \\
{ }^{3} S^{e}\end{array}$ & $\begin{array}{l}1.23 \mathrm{E}-11 \\
3.23 \mathrm{E}-12 \\
3.12 \mathrm{E}-12 \\
3.05 \mathrm{E}-12 \\
2.91 \mathrm{E}-12 \\
2.36 \mathrm{E}-12 \\
1.70 \mathrm{E}-12 \\
1.22 \mathrm{E}-12 \\
1.21 \mathrm{E}-12 \\
1.10 \mathrm{E}-12 \\
7.41 \mathrm{E}-13 \\
4.49 \mathrm{E}-13 \\
4.28 \mathrm{E}-13 \\
4.12 \mathrm{E}-13 \\
3.14 \mathrm{E}-13 \\
3.06 \mathrm{E}-13 \\
2.23 \mathrm{E}-13 \\
2.06 \mathrm{E}-13 \\
1.72 \mathrm{E}-13 \\
1.67 \mathrm{E}-13\end{array}$ & $\begin{array}{l}1 s^{2} 2 p^{2} P^{o} 3 d \\
1 s^{2} 2 p^{2} \\
1 s^{2} 2 p^{2} \\
1 s^{2} 2 s^{2} S^{e} 2 p \\
1 s^{2} 2 s^{2} S^{e} 2 p \\
1 s^{2} 2 p^{2} P^{o} 3 d \\
1 s^{2} 2 s^{2} S^{e} 4 f \\
1 s^{2} 2 s^{2} S^{e} 3 d \\
1 s^{2} 2 p^{2} P^{o} 3 d \\
1 s^{2} 2 s^{2} S^{e} 4 d \\
1 s^{2} 2 s^{2} \\
1 s^{2} 2 p^{2} P^{o} 3 p \\
1 s^{2} 2 s^{2} S^{e} 5 f \\
1 s^{2} 2 s^{2} S^{e} 4 p \\
1 s^{2} 2 s^{2} S^{e} 3 p \\
1 s^{2} 2 p^{2} P^{o} 3 p \\
1 s^{2} 2 p^{2} P^{o} 3 d \\
1 s^{2} 2 s^{2} S^{e} 5 f \\
1 s^{2} 2 p^{2} P^{o} 3 p \\
1 s^{2} 2 s^{2} S^{e} 5 p\end{array}$ & $\begin{array}{l}{ }^{3} F^{o} \\
{ }^{1} D^{e} \\
{ }^{3} P^{e} \\
{ }^{3} P^{o} \\
{ }^{1} P^{o} \\
{ }^{1} F^{o} \\
{ }^{1} F^{o} \\
{ }^{3} D^{e} \\
{ }^{1} D^{o} \\
{ }^{3} D^{e} \\
{ }^{1} S^{e} \\
{ }^{3} D^{e} \\
{ }^{1} F^{o} \\
{ }^{1} P^{o} \\
{ }^{3} P^{o} \\
{ }^{1} D^{e} \\
{ }^{3} P^{o} \\
{ }^{3} F^{o} \\
{ }^{3} S^{e} \\
{ }^{1} P^{o}\end{array}$ & $\begin{array}{l}4.11 \mathrm{E}-12 \\
2.92 \mathrm{E}-12 \\
2.73 \mathrm{E}-12 \\
1.48 \mathrm{E}-12 \\
1.44 \mathrm{E}-12 \\
8.11 \mathrm{E}-13 \\
7.40 \mathrm{E}-13 \\
5.47 \mathrm{E}-13 \\
5.32 \mathrm{E}-13 \\
4.86 \mathrm{E}-13 \\
3.92 \mathrm{E}-13 \\
3.82 \mathrm{E}-13 \\
3.67 \mathrm{E}-13 \\
3.49 \mathrm{E}-13 \\
3.33 \mathrm{E}-13 \\
3.20 \mathrm{E}-13 \\
2.60 \mathrm{E}-13 \\
2.45 \mathrm{E}-13 \\
2.40 \mathrm{E}-13 \\
2.37 \mathrm{E}-13\end{array}$ & $\begin{array}{l}1 s^{2} 2 p^{2} P^{o} 3 d \\
1 s^{2} 2 p^{2} \\
1 s^{2} 2 p^{2} \\
1 s^{2} 2 s^{2} S^{e} 2 p \\
1 s^{2} 2 s^{2} S^{e} 2 p \\
1 s^{2} 2 s^{2} S^{e} 4 f \\
1 s^{2} 2 p^{2} P^{o} 3 d \\
1 s^{2} 2 s^{2} S^{e} 3 d \\
1 s^{2} 2 p^{2} P^{o} 3 d \\
1 s^{2} 2 s^{2} \\
1 s^{2} 2 s^{2} S^{e} 4 d \\
1 s^{2} 2 s^{2} S^{e} 3 p \\
1 s^{2} 2 s^{2} S^{e} 5 f \\
1 s^{2} 2 s^{2} S^{e} 5 f \\
1 s^{2} 2 p^{2} P^{o} 3 p \\
1 s^{2} 2 p^{2} P^{o} 3 p \\
1 s^{2} 2 s^{2} S^{e} 4 d \\
1 s^{2} 2 p^{2} P^{o} 3 d \\
1 s^{2} 2 s^{2} S^{e} 4 f \\
1 s^{2} 2 s^{2} S^{e} 5 p\end{array}$ & $\begin{array}{l}{ }^{3} F^{o} \\
{ }^{1} D^{e} \\
{ }^{3} P^{e} \\
{ }^{3} P^{o} \\
{ }^{1} P^{o} \\
{ }^{1} F^{o} \\
{ }^{1} F^{o} \\
{ }^{3} D^{e} \\
{ }^{1} D^{o} \\
{ }^{1} S^{e} \\
{ }^{3} D^{e} \\
{ }^{3} P^{o} \\
{ }^{1} F^{o} \\
{ }^{3} F^{o} \\
{ }^{1} D^{e} \\
{ }^{3} D^{e} \\
{ }^{1} D^{e} \\
{ }^{3} P^{o} \\
{ }^{3} F^{o} \\
{ }^{1} P^{o}\end{array}$ & $\begin{array}{l}2.32 \mathrm{E}-12 \\
1.83 \mathrm{E}-12 \\
1.52 \mathrm{E}-12 \\
1.07 \mathrm{E}-12 \\
6.49 \mathrm{E}-13 \\
4.88 \mathrm{E}-13 \\
4.44 \mathrm{E}-13 \\
3.61 \mathrm{E}-13 \\
3.43 \mathrm{E}-13 \\
3.12 \mathrm{E}-13 \\
2.92 \mathrm{E}-13 \\
2.33 \mathrm{E}-13 \\
2.24 \mathrm{E}-13 \\
1.97 \mathrm{E}-13 \\
1.94 \mathrm{E}-13 \\
1.89 \mathrm{E}-13 \\
1.78 \mathrm{E}-13 \\
1.72 \mathrm{E}-13 \\
1.69 \mathrm{E}-13 \\
1.57 \mathrm{E}-13\end{array}$ \\
\hline $\begin{array}{l}\text { Sum } \ldots \ldots \ldots \ldots \ldots \ldots \\
\text { Total .................. } \\
\text { Contribution }(\%) \ldots \ldots\end{array}$ & & $\begin{array}{l}2.58 \mathrm{E}-10 \\
3.23 \mathrm{E}-10 \\
80.0 \%\end{array}$ & & & $\begin{array}{l}3.57 \mathrm{E}-11 \\
4.97 \mathrm{E}-11 \\
72.0 \%\end{array}$ & & & $\begin{array}{l}1.89 \mathrm{E}-11 \\
2.48 \mathrm{E}-11 \\
76.0 \%\end{array}$ & & & $\begin{array}{l}1.13 \mathrm{E}-11 \\
1.53 \mathrm{E}-11 \\
74.0 \%\end{array}$ \\
\hline \multicolumn{12}{|c|}{$\mathrm{N}_{\mathrm{I}}$} \\
\hline $\begin{array}{l}2 s^{2} 2 p^{3} \\
2 s^{2} 2 p^{3} \\
2 s^{2} 2 p^{3} \\
2 s^{2} 2 p 2^{3} P^{e} 3 p \\
2 s^{2} 2 p 2{ }^{3} P^{e} 3 d \\
2 s^{2} 2 p 2^{3} P^{e} 3 d \\
2 s^{2} 2 p 2{ }^{3} P^{e} 4 d \\
2 s^{2} 2 p 2{ }^{3} P^{e} 3 p \\
2 s^{2} 2 p 2^{3} P^{e} 3 d \\
2 s^{2} 2 p 2^{3} P^{e} 3 d \\
2 s^{2} 2 p 2{ }^{3} P^{e} 4 d \\
2 s^{2} 2 p 2^{3} P^{e} 4 f \\
2 s^{2} 2 p 2{ }^{3} P^{e} 4 p \\
2 s^{2} 2 p 2{ }^{3} P^{e} 5 d \\
2 s^{2} 2 p 2{ }^{3} P^{e} 5 f \\
2 s^{2} 2 p 2{ }^{3} P^{e} 3 d \\
2 s^{2} 2 p 2{ }^{3} P^{e} 4 d \\
2 s^{2} 2 p 22^{3} P^{e} 4 f \\
2 s^{2} 2 p 22^{3} P^{e} 5 f \\
2 s^{2} 2 p 2^{3} P^{e} 6 f\end{array}$ & $\begin{array}{l}{ }^{4} S^{o} \\
{ }^{2} D^{o} \\
{ }^{2} P^{o} \\
{ }^{4} D^{o} \\
{ }^{4} F^{e} \\
{ }^{4} D^{e} \\
{ }^{4} F^{e} \\
{ }^{4} P^{o} \\
{ }^{2} F^{e} \\
{ }^{4} P^{e} \\
{ }^{4} D^{e} \\
{ }^{4} G^{o} \\
{ }^{4} D^{o} \\
{ }^{4} F^{e} \\
{ }^{4} G^{o} \\
{ }^{2} D^{e} \\
{ }^{2} F^{e} \\
{ }^{4} F^{o} \\
{ }^{4} F^{o} \\
{ }^{4} G^{o}\end{array}$ & $\begin{array}{l}7.85 \mathrm{E}-13 \\
6.10 \mathrm{E}-13 \\
3.59 \mathrm{E}-13 \\
1.04 \mathrm{E}-13 \\
1.02 \mathrm{E}-13 \\
6.34 \mathrm{E}-14 \\
6.05 \mathrm{E}-14 \\
5.57 \mathrm{E}-14 \\
4.83 \mathrm{E}-14 \\
3.97 \mathrm{E}-14 \\
3.96 \mathrm{E}-14 \\
3.94 \mathrm{E}-14 \\
3.63 \mathrm{E}-14 \\
3.54 \mathrm{E}-14 \\
3.45 \mathrm{E}-14 \\
2.96 \mathrm{E}-14 \\
2.92 \mathrm{E}-14 \\
2.88 \mathrm{E}-14 \\
2.57 \mathrm{E}-14 \\
2.51 \mathrm{E}-14\end{array}$ & $\begin{array}{l}2 s^{2} 2 p^{3} \\
2 s^{2} 2 p^{3} \\
2 s^{2} 2 p^{3} \\
2 s^{2} 2 p 2{ }^{3} P^{e} 3 p \\
2 s^{2} 2 p 2{ }^{3} P^{e} 3 d \\
2 s^{2} 2 p 2{ }^{3} P^{e} 3 d \\
2 s^{2} 2 p 2{ }^{3} P^{e} 4 d \\
2 s^{2} 2 p 2{ }^{1} D^{e} 3 p \\
2 s^{2} 2 p 2{ }^{3} P^{e} 3 p \\
2 s^{2} 2 p 2{ }^{3} P^{e} 3 d \\
2 s^{2} 2 p 2{ }^{3} P^{e} 3 d \\
2 s^{2} 2 p 2{ }^{3} P^{e} 4 d \\
2 s^{2} 2 p 2{ }^{3} P^{e} 4 f \\
2 s^{2} 2 p 2{ }^{3} P^{e} 4 p \\
2 s^{2} 2 p 2{ }^{3} P^{e} 5 d \\
2 s^{2} 2 p 2{ }^{3} P^{e} 5 f \\
2 s^{2} 2 p 2{ }^{3} P^{e} 3 d \\
2 s^{2} 2 p 2{ }^{3} P^{e} 4 d \\
2 s^{2} 2 p 2{ }^{1} D^{e} 3 p \\
2 s^{2} 2 p 2{ }^{3} P^{e} 3 p\end{array}$ & $\begin{array}{l}{ }^{2} D^{o} \\
{ }^{4} S^{o} \\
{ }^{2} P^{o} \\
{ }^{4} D^{o} \\
{ }^{4} F^{e} \\
{ }^{4} D^{e} \\
{ }^{4} F^{e} \\
{ }^{2} D^{o} \\
{ }^{4} P^{o} \\
{ }^{2} F^{e} \\
{ }^{4} P^{e} \\
{ }^{4} D^{e} \\
{ }^{4} G^{o} \\
{ }^{4} D^{o} \\
{ }^{4} F^{e} \\
{ }^{4} G^{o} \\
{ }^{2} D^{e} \\
{ }^{2} F^{e} \\
{ }^{2} F^{o} \\
{ }^{2} D^{o}\end{array}$ & $\begin{array}{l}4.02 \mathrm{E}-13 \\
2.52 \mathrm{E}-13 \\
1.17 \mathrm{E}-13 \\
3.11 \mathrm{E}-14 \\
3.02 \mathrm{E}-14 \\
1.87 \mathrm{E}-14 \\
1.80 \mathrm{E}-14 \\
1.77 \mathrm{E}-14 \\
1.65 \mathrm{E}-14 \\
1.43 \mathrm{E}-14 \\
1.17 \mathrm{E}-14 \\
1.17 \mathrm{E}-14 \\
1.08 \mathrm{E}-14 \\
1.06 \mathrm{E}-14 \\
1.06 \mathrm{E}-14 \\
9.50 \mathrm{E}-15 \\
8.69 \mathrm{E}-15 \\
8.66 \mathrm{E}-15 \\
8.66 \mathrm{E}-15 \\
8.12 \mathrm{E}-15\end{array}$ & $\begin{array}{l}2 s^{2} 2 p^{3} \\
2 s^{2} 2 p^{3} \\
2 s^{2} 2 p^{3} \\
2 s^{2} 2 p 2{ }^{1} D^{e} 3 p \\
2 s^{2} 2 p 2{ }^{3} P^{e} 3 p \\
2 s^{2} 2 p 2{ }^{3} P^{e} 3 d \\
2 s^{2} 2 p 2{ }^{1} D^{e} 3 p \\
2 s^{2} 2 p 2{ }^{3} P^{e} 3 d \\
2 s^{2} 2 p 2{ }^{3} P^{e} 4 d \\
2 s^{2} 2 p 2{ }^{3} P^{e} 3 p \\
2 \\
2 s^{2} 2 p 2{ }^{3} P^{e} 4 d \\
2 s^{2} 2 p 2{ }^{3} P^{e} 4 p \\
2 s^{2} 2 p 2{ }^{3} P^{e} 3 d \\
2 s^{2} 2 p 2{ }^{3} P^{e} 3 p \\
2 s^{2} 2 p 2{ }^{3} P^{e} 5 d \\
2 s^{2} 2 p 2{ }^{3} P^{e} 4 p \\
2 s 2 p^{4} \\
2 s^{2} 2 p 2{ }^{3} P^{e} 4 f \\
2 s^{2} 2 p 2{ }^{3} P^{e} 4 d\end{array}$ & $\begin{array}{l}{ }^{2} D^{o} \\
{ }^{4} S^{o} \\
{ }^{2} P^{o} \\
{ }^{2} D^{o} \\
{ }^{4} D^{o} \\
{ }^{4} F^{e} \\
{ }^{2} F^{o} \\
{ }^{4} D^{e} \\
{ }^{4} F^{e} \\
{ }^{4} P^{o} \\
{ }^{2} F^{e} \\
{ }^{4} D^{e} \\
{ }^{2} D^{o} \\
{ }^{4} P^{e} \\
{ }^{2} D^{o} \\
{ }^{4} F^{e} \\
{ }^{4} D^{o} \\
{ }^{4} P^{e} \\
{ }^{4} G^{o} \\
{ }^{2} F^{e}\end{array}$ & $\begin{array}{l}2.95 \mathrm{E}-13 \\
1.21 \mathrm{E}-13 \\
7.34 \mathrm{E}-14 \\
1.52 \mathrm{E}-14 \\
1.11 \mathrm{E}-14 \\
1.08 \mathrm{E}-14 \\
8.57 \mathrm{E}-15 \\
6.61 \mathrm{E}-15 \\
6.51 \mathrm{E}-15 \\
5.85 \mathrm{E}-15 \\
5.07 \mathrm{E}-15 \\
4.15 \mathrm{E}-15 \\
4.13 \mathrm{E}-15 \\
4.13 \mathrm{E}-15 \\
3.95 \mathrm{E}-15 \\
3.82 \mathrm{E}-15 \\
3.67 \mathrm{E}-15 \\
3.52 \mathrm{E}-15 \\
3.20 \mathrm{E}-15 \\
3.09 \mathrm{E}-15\end{array}$ & $\begin{array}{l}2 s^{2} 2 p^{3} \\
2 s^{2} 2 p^{3} \\
2 s^{2} 2 p^{3} \\
2 s^{2} 2 p 2{ }^{1} D^{e} 3 p \\
2 s^{2} 2 p 2{ }^{3} P^{e} 3 p \\
2 s^{2} 2 p 2{ }^{3} P^{e} 3 d \\
2 s^{2} 2 p 2{ }^{1} D^{e} 3 p \\
2 s 2 p^{4} \\
2 s^{2} 2 p 2{ }^{3} P^{e} 4 d \\
2 s^{2} 2 p 2{ }^{3} P^{e} 3 d \\
2 s^{2} 2 p 2{ }^{3} P^{e} 3 p \\
2 s^{2} 2 p 2{ }^{3} P^{e} 3 d \\
2 s^{2} 2 p 2{ }^{3} P^{e} 3 p \\
2 s^{2} 2 p 2{ }^{3} P^{e} 4 d \\
2 s^{2} 2 p 2{ }^{3} P^{e} 3 d \\
2 s^{2} 2 p 2{ }^{3} P^{e} 4 p \\
2 s^{2} 2 p 2{ }^{3} P^{e} 5 d \\
2 s^{2} 2 p 2{ }^{3} P^{e} 3 s \\
2 s^{2} 2 p 2{ }^{3} P^{e} 4 p \\
2 s^{2} 2 p 2{ }^{3} P^{e} 4 d\end{array}$ & $\begin{array}{l}{ }^{2} D^{o} \\
{ }^{4} S^{o} \\
{ }^{2} P^{o} \\
{ }^{2} D^{o} \\
{ }^{4} D^{o} \\
{ }^{4} F^{e} \\
{ }^{2} F^{o} \\
{ }^{4} P^{e} \\
{ }^{4} F^{e} \\
{ }^{4} D^{e} \\
{ }^{4} P^{o} \\
{ }^{2} F^{e} \\
{ }^{2} D^{o} \\
{ }^{4} D^{e} \\
{ }^{4} P^{e} \\
{ }^{2} D^{o} \\
{ }^{4} F^{e} \\
{ }^{4} P^{e} \\
{ }^{4} D^{o} \\
{ }^{2} F^{e}\end{array}$ & $\begin{array}{l}2.03 \mathrm{E}-13 \\
9.35 \mathrm{E}-14 \\
5.57 \mathrm{E}-14 \\
8.33 \mathrm{E}-15 \\
6.58 \mathrm{E}-15 \\
6.30 \mathrm{E}-15 \\
5.03 \mathrm{E}-15 \\
4.61 \mathrm{E}-15 \\
3.80 \mathrm{E}-15 \\
3.79 \mathrm{E}-15 \\
3.43 \mathrm{E}-15 \\
2.93 \mathrm{E}-15 \\
2.57 \mathrm{E}-15 \\
2.38 \mathrm{E}-15 \\
2.35 \mathrm{E}-15 \\
2.28 \mathrm{E}-15 \\
2.23 \mathrm{E}-15 \\
2.19 \mathrm{E}-15 \\
2.10 \mathrm{E}-15 \\
1.78 \mathrm{E}-15\end{array}$ \\
\hline $\begin{array}{l}\text { Sum } \ldots \ldots \ldots \ldots \ldots \ldots \\
\text { Total .................. } \\
\text { Contribution }(\%) \ldots \ldots\end{array}$ & & $\begin{array}{l}2.55 \mathrm{E}-12 \\
7.38 \mathrm{E}-12 \\
35.0 \%\end{array}$ & & & $\begin{array}{l}1.02 \mathrm{E}-12 \\
1.89 \mathrm{E}-12 \\
54.0 \%\end{array}$ & & & $\begin{array}{l}5.92 \mathrm{E}-13 \\
8.10 \mathrm{E}-13 \\
73.0 \%\end{array}$ & & & $\begin{array}{l}4.15 \mathrm{E}-13 \\
5.28 \mathrm{E}-13 \\
79.0 \%\end{array}$ \\
\hline \multicolumn{12}{|c|}{$\mathrm{N}$ III } \\
\hline 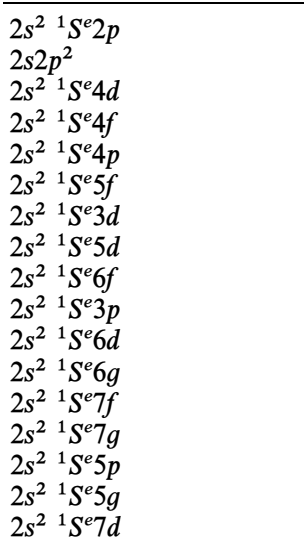 & $\begin{array}{l}{ }^{2} P^{o} \\
{ }^{2} D^{e} \\
{ }^{2} D^{e} \\
{ }^{2} F^{o} \\
{ }^{2} P^{o} \\
{ }^{2} F^{o} \\
{ }^{2} D^{e} \\
{ }^{2} D^{e} \\
{ }^{2} F^{o} \\
{ }^{2} P^{o} \\
{ }^{2} D^{e} \\
{ }^{2} G^{e} \\
{ }^{2} F^{o} \\
{ }^{2} G^{e} \\
{ }^{2} P^{o} \\
{ }^{2} G^{e} \\
{ }^{2} D^{e}\end{array}$ & $\begin{array}{l}1.93 \mathrm{E}-11 \\
5.08 \mathrm{E}-12 \\
1.65 \mathrm{E}-12 \\
1.23 \mathrm{E}-12 \\
1.17 \mathrm{E}-12 \\
1.14 \mathrm{E}-12 \\
1.13 \mathrm{E}-12 \\
1.11 \mathrm{E}-12 \\
8.72 \mathrm{E}-13 \\
8.26 \mathrm{E}-13 \\
7.27 \mathrm{E}-13 \\
6.84 \mathrm{E}-13 \\
6.39 \mathrm{E}-13 \\
6.06 \mathrm{E}-13 \\
6.01 \mathrm{E}-13 \\
5.90 \mathrm{E}-13 \\
4.98 \mathrm{E}-13\end{array}$ & 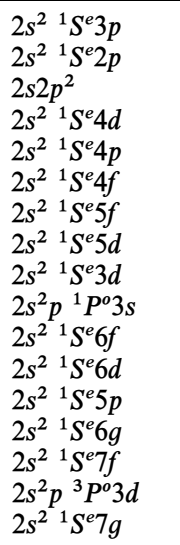 & $\begin{array}{l}{ }^{2} P^{o} \\
{ }^{2} P^{o} \\
{ }^{2} D^{e} \\
{ }^{2} D^{e} \\
{ }^{2} P^{o} \\
{ }^{2} F^{o} \\
{ }^{2} F^{o} \\
{ }^{2} D^{e} \\
{ }^{2} D^{e} \\
{ }^{2} P^{o} \\
{ }^{2} F^{o} \\
{ }^{2} D^{e} \\
{ }^{2} P^{o} \\
{ }^{2} G^{e} \\
{ }^{2} F^{o} \\
{ }^{2} F^{o} \\
{ }^{2} G^{e}\end{array}$ & $\begin{array}{l}6.63 \mathrm{E}-12 \\
6.47 \mathrm{E}-12 \\
1.73 \mathrm{E}-12 \\
5.16 \mathrm{E}-13 \\
4.13 \mathrm{E}-13 \\
3.89 \mathrm{E}-13 \\
3.59 \mathrm{E}-13 \\
3.46 \mathrm{E}-13 \\
3.37 \mathrm{E}-13 \\
2.94 \mathrm{E}-13 \\
2.72 \mathrm{E}-13 \\
2.28 \mathrm{E}-13 \\
2.26 \mathrm{E}-13 \\
2.09 \mathrm{E}-13 \\
1.99 \mathrm{E}-13 \\
1.95 \mathrm{E}-13 \\
1.85 \mathrm{E}-13\end{array}$ & $\begin{array}{l}2 s^{2}{ }^{1} S^{e} 3 p \\
2 s 2 p^{2} \\
2 s^{2}{ }^{1} S^{e} 2 p \\
2 s 2 p^{2} \\
2 s^{2}{ }^{1} S^{e} 4 d \\
2 s^{2} p^{3} P^{o} 3 p \\
2 s^{2}{ }^{1} S^{e} 3 d \\
2 s^{2} p^{3} P^{o} 3 d \\
2 s^{2} p p{ }^{1} P^{o} 3 s \\
2 s 2 p^{2} \\
2 s^{2}{ }^{1} S^{e} 4 p \\
2 s^{2}{ }^{1} S^{e} 4 f \\
2 s^{2}{ }^{1} S^{e} 5 f \\
2 s^{2}{ }^{1} S^{e} 5 d \\
2 s^{2} p^{3} P^{o} 3 d \\
2 p^{3} \\
2 s^{2}{ }^{1} S^{e} 6 f\end{array}$ & $\begin{array}{l}{ }^{2} P^{o} \\
{ }^{2} D^{e} \\
{ }^{2} P^{o} \\
{ }^{2} S^{e} \\
{ }^{2} D^{e} \\
{ }^{2} D^{e} \\
{ }^{2} D^{e} \\
{ }^{2} P^{o} \\
{ }^{2} P^{o} \\
{ }^{2} P^{e} \\
{ }^{2} P^{o} \\
{ }^{2} F^{o} \\
{ }^{2} F^{o} \\
{ }^{2} D^{e} \\
{ }^{2} F^{o} \\
{ }^{2} P^{o} \\
{ }^{2} F^{o}\end{array}$ & $\begin{array}{l}4.91 \mathrm{E}-12 \\
4.35 \mathrm{E}-12 \\
2.87 \mathrm{E}-12 \\
5.09 \mathrm{E}-13 \\
2.64 \mathrm{E}-13 \\
2.41 \mathrm{E}-13 \\
2.32 \mathrm{E}-13 \\
2.13 \mathrm{E}-13 \\
1.82 \mathrm{E}-13 \\
1.74 \mathrm{E}-13 \\
1.72 \mathrm{E}-13 \\
1.63 \mathrm{E}-13 \\
1.52 \mathrm{E}-13 \\
1.46 \mathrm{E}-13 \\
1.24 \mathrm{E}-13 \\
1.23 \mathrm{E}-13 \\
1.14 \mathrm{E}-13\end{array}$ & $\begin{array}{l}2 s 2 p^{2} \\
2 s^{2}{ }^{1} S^{e} 3 p \\
2 s^{2}{ }^{1} S^{e} 2 p \\
2 s^{2}{ }^{1} S^{e} 3 d \\
2 s 2 p^{2} \\
2 s 2 p^{2} \\
2 s^{2} p{ }^{3} P^{o} 3 p \\
2 s^{2}{ }^{1} S^{e} 4 d \\
2 s^{2} p^{3} P^{o} 3 d \\
2 s^{2}{ }^{1} S^{e} 4 p \\
2 s^{2}{ }^{1} S^{e} 4 f \\
2 s^{2}{ }^{1} S^{e} 5 f\end{array}$ & $\begin{array}{l}{ }^{2} D^{e} \\
{ }^{2} P^{o} \\
{ }^{2} P^{o} \\
{ }^{2} D^{e} \\
{ }^{2} S^{e} \\
{ }^{2} P^{e} \\
{ }^{2} D^{e} \\
{ }^{2} D^{e} \\
{ }^{2} P^{o} \\
{ }^{2} P^{o} \\
{ }^{2} F^{o} \\
{ }^{2} F^{o}\end{array}$ & $\begin{array}{l}4.55 \mathrm{E}-12 \\
2.49 \mathrm{E}-12 \\
2.10 \mathrm{E}-12 \\
7.07 \mathrm{E}-13 \\
5.85 \mathrm{E}-13 \\
3.84 \mathrm{E}-13 \\
2.11 \mathrm{E}-13 \\
1.84 \mathrm{E}-13 \\
1.79 \mathrm{E}-13 \\
1.21 \mathrm{E}-13 \\
1.05 \mathrm{E}-13 \\
9.87 \mathrm{E}-14\end{array}$ \\
\hline
\end{tabular}


TABLE 4-Continued

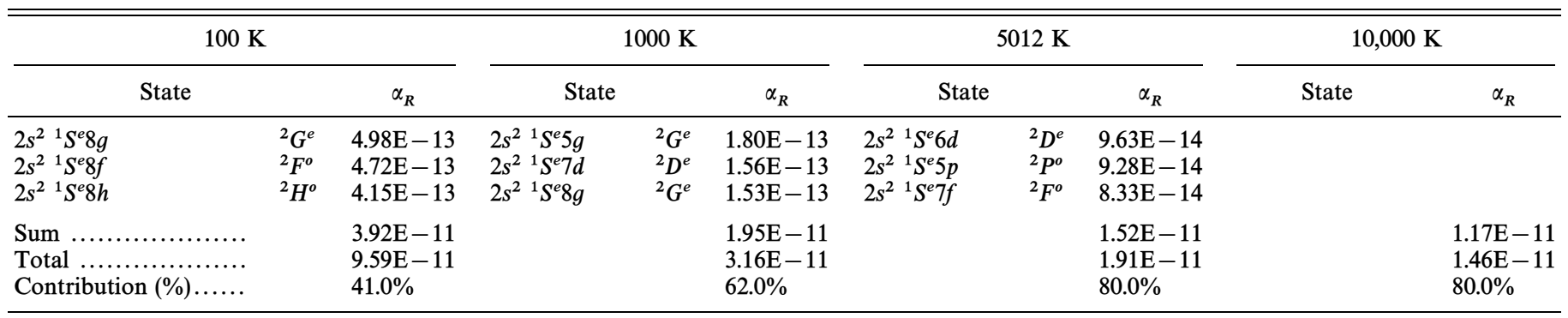

Note.-State-specific recombination rate coefficients (in units of $\mathrm{cm}^{3} \mathrm{~s}^{-1}$ ) of the top 20 individual states of $\mathrm{C}$ III, $\mathrm{N} \mathrm{I}$, and N III in order of their contributions to the total $\alpha_{R}$ at temperatures $T=100,1000,5012$, and $10,000 \mathrm{~K}$.

the conservation of flux, photons and electrons, between DR and EIE. The conservation condition is satisfied since all radiative and autoionization channels are coupled and therefore at the threshold(s) $\langle\Omega(D R)\rangle$ should match $\Omega$ (EIE). We invoke this theoretical criterion as a test of the numerical accuracy of the rather complex calculations involving a large number of coupled channels. We compare the two sets of values for each ion in Table 3. The agreement between the numbers within a few percent indicates conservation of flux such that the flux trapped in the resonances below thresholds due to DR equals that released (scattered) at the thresholds due to EIE. The equality between the two collision strengths at the threshold may not hold in complicated cases with closely spaced energy levels and overlapping Rydberg series of resonances (a discussion is given in NP).

The total recombination rate coefficients, $\alpha_{R}(T)$, are computed over a wide range of temperatures, $1 \leq \log _{10}(T) \leq 9$, at a fine temperature mesh, $\Delta T=0.1$, for easy interpolation. The values are given in Table 5 for the carbon ions and in Table 6 for nitrogen ions. $\alpha_{R}(T)$ for $\mathrm{C}$ I, C II, N II (Nahar 1996a) are also presented here for completeness.

Comparison of the present $\alpha_{R}(T)$ values with the previous works are made in Figures 7 and 8 . The solid lines are the present total recombination rate coefficients, while the dashed lines correspond to the RR rates of Aldrovandi \& Pequignot (1973), dotted lines to the low-temperature DR rates by Nussbaumer \& Storey (1983), and the dot-dashed

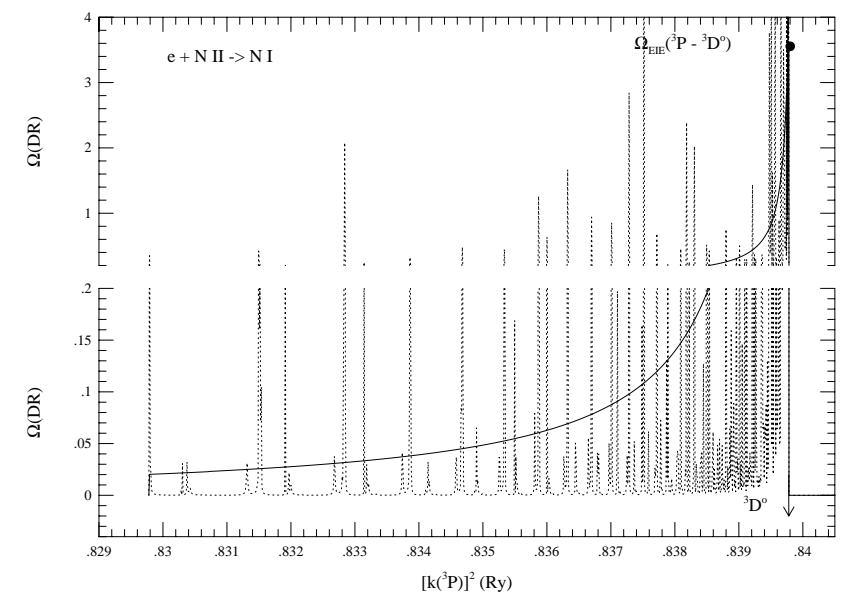

FIG. 6.-Collision strengths for DR to $\mathrm{N}$ I: detailed $\Omega(\mathrm{DR})$ with resonances (dotted line), and averaged over resonances (solid line) in the region below and at the first excited threshold, ${ }^{3} D^{o}$, for dipole allowed transition from the ground state ${ }^{3} P$. The filled circle represents the calculated excitation collision strength, $\Omega_{\mathrm{EIE}}$, at the ${ }^{3} D^{o}$ threshold. lines to the high-temperature DR rates by Shull \& van Steenberg (1982a, 1982b) (fitted from the work by Jacobs et al. 1978). The filled circles are calculated DR rates for $C$ in in Figure $7 a$ by Badnell (1987), for C IV in Figure $7 c$ by Badnell, Pindzola, \& Griffin (1990), and for N III in Figure $8 c$ by Badnell $(1987,1988)$. Our results confirm the existence of low-temperature DR "bumps" in C II (Fig. 7a), C III (Fig. 7b), N I (Fig. 8a), and the small "shoulder" in N II (Fig. 8b) as obtained by Nussbaumer \& Storey (1983). However, present results differ from those of Nussbaumer \& Storey (1983) for N III and N VI in terms of position and magnitude of these low- $T$ DR bumps. The isolated resonance approximations employed by Nussbaumer \& Storey (1983) and Badnell for N III show agreement with each other. We note that for $\mathrm{C}$ IV the present rates at high temperatures lie between the two earlier sets of results; however, the present values of $\alpha_{R}$ yield ionization fractions for C IV in almost exact agreement with Arnaud \& Rothenflug (1985), as shown in Figure 9.

An important atomic effect that decreases the contribution to DR is autoionization into excited states of the target ion, first discussed by Jacobs et al. (1978). It is included in the present $\mathrm{CC}$ work more precisely, since all electron-ion channels are coupled, in contrast to previous works using the distorted wave approximation, which couples only the initial and the final ones. As shown in the detailed experimental and theoretical cross sections given in Nahar, Zhang, \& Pradhan (1997b), the contribution to DR from transitions other than the first one (usually referred to as the "resonance transition," although that is a misnomer) is small because of radiationless decay into the excited autoionization channels. The consequent reduction in DR has been shown to be large in cases in which a large number of target states are coupled, e.g., Fe II (Nahar 1997).

\subsection{Ionization Fractions}

The ionization fractions in coronal equilibrium are computed by solving a set of coupled equations for all ionization stages as in equation (2). Electron impact ionization rates given by Bell et al. (1983) are used, together with the new total $\alpha_{R}(T)$. Figures 9 and 10 show the present ionic fractions (solid lines) compared to the previous work by Arnaud \& Rothenflug (1985) (dashed lines). The results of Arnaud \& Rothenflug (1985) agree well with those given recently by Sutherland \& Dopita (1993). Although the general agreement is good, as seen in the figures, significant differences can be noticed near the peak values and in the extent of ionization as a function of temperature where rapid variations occur. In addition, the largest differences are in the peak values for Be-like and $\mathrm{H}$-like ions. We have 
TABLE 5

Total Recombination Rate Coefficients for Carbon Ions

\begin{tabular}{|c|c|c|c|c|c|c|}
\hline \multirow[b]{2}{*}{$\log _{10} T$} & \multicolumn{6}{|c|}{$\alpha_{R}(T)$} \\
\hline & $\mathrm{C}_{\mathrm{I}}$ & $\mathrm{C}$ II & C III & C IV & $\mathrm{C} \mathrm{v}$ & C VI \\
\hline $1.0 \ldots$ & $3.61 \mathrm{E}-11$ & $1.63 \mathrm{E}-10$ & $9.01 \mathrm{E}-10$ & $6.03 E-10$ & $1.05 \mathrm{E}-09$ & $1.60 \mathrm{E}-09$ \\
\hline $1.1 .$. & $3.15 \mathrm{E}-11$ & $1.42 \mathrm{E}-10$ & $8.12 \mathrm{E}-10$ & $5.29 \mathrm{E}-10$ & $9.25 \mathrm{E}-10$ & $1.41 \mathrm{E}-09$ \\
\hline $1.2 \ldots$ & $2.75 \mathrm{E}-11$ & $1.25 \mathrm{E}-10$ & $7.35 \mathrm{E}-10$ & $4.65 \mathrm{E}-10$ & $8.13 E-10$ & $1.24 \mathrm{E}-09$ \\
\hline $1.3 \ldots$ & $2.40 \mathrm{E}-11$ & $1.09 \mathrm{E}-10$ & $6.68 \mathrm{E}-10$ & $4.07 \mathrm{E}-10$ & $7.14 \mathrm{E}-10$ & $1.09 \mathrm{E}-09$ \\
\hline $1.4 \ldots$ & $2.10 \mathrm{E}-11$ & $9.56 \mathrm{E}-11$ & $6.09 \mathrm{E}-10$ & $3.56 \mathrm{E}-10$ & $6.28 \mathrm{E}-10$ & $9.60 \mathrm{E}-10$ \\
\hline $1.5 \ldots$ & $1.83 \mathrm{E}-11$ & $8.35 \mathrm{E}-11$ & $5.57 \mathrm{E}-10$ & $3.12 \mathrm{E}-10$ & $5.51 \mathrm{E}-10$ & $8.44 \mathrm{E}-10$ \\
\hline $1.6 \ldots$ & $1.59 \mathrm{E}-11$ & $7.30 \mathrm{E}-11$ & $5.09 \mathrm{E}-10$ & $2.72 \mathrm{E}-10$ & $4.83 \mathrm{E}-10$ & $7.41 \mathrm{E}-10$ \\
\hline $1.7 \ldots$ & $1.39 \mathrm{E}-11$ & $6.38 \mathrm{E}-11$ & $4.62 \mathrm{E}-10$ & $2.38 \mathrm{E}-10$ & $4.23 \mathrm{E}-10$ & $6.50 \mathrm{E}-10$ \\
\hline $1.8 \ldots$ & $1.21 \mathrm{E}-11$ & $5.56 \mathrm{E}-11$ & $4.16 \mathrm{E}-10$ & $2.07 \mathrm{E}-10$ & $3.70 \mathrm{E}-10$ & $5.71 \mathrm{E}-10$ \\
\hline $1.9 \ldots$ & $1.05 \mathrm{E}-11$ & $4.86 \mathrm{E}-11$ & $3.70 \mathrm{E}-10$ & $1.81 \mathrm{E}-10$ & $3.24 \mathrm{E}-10$ & $5.00 \mathrm{E}-10$ \\
\hline $2.0 \ldots \ldots$ & $9.13 \mathrm{E}-12$ & $4.24 \mathrm{E}-11$ & $3.23 \mathrm{E}-10$ & $1.58 \mathrm{E}-10$ & $2.83 \mathrm{E}-10$ & $4.38 \mathrm{E}-10$ \\
\hline $2.1 \ldots$ & $7.94 \mathrm{E}-12$ & $3.70 \mathrm{E}-11$ & $2.78 \mathrm{E}-10$ & $1.37 \mathrm{E}-10$ & $2.47 \mathrm{E}-10$ & $3.83 \mathrm{E}-10$ \\
\hline $2.2 \ldots$ & $6.89 \mathrm{E}-12$ & $3.22 \mathrm{E}-11$ & $2.35 \mathrm{E}-10$ & $1.20 \mathrm{E}-10$ & $2.16 \mathrm{E}-10$ & $3.35 \mathrm{E}-10$ \\
\hline $2.3 \ldots$ & $5.99 \mathrm{E}-12$ & $2.81 \mathrm{E}-11$ & $1.96 \mathrm{E}-10$ & $1.04 \mathrm{E}-10$ & $1.88 \mathrm{E}-10$ & $2.93 \mathrm{E}-10$ \\
\hline $2.4 \ldots \ldots$ & $5.20 \mathrm{E}-12$ & $2.45 \mathrm{E}-11$ & $1.61 \mathrm{E}-10$ & $9.03 \mathrm{E}-11$ & $1.64 \mathrm{E}-10$ & $2.56 \mathrm{E}-10$ \\
\hline $2.5 \ldots$ & $4.51 \mathrm{E}-12$ & $2.13 E-11$ & $1.32 \mathrm{E}-10$ & $7.86 \mathrm{E}-11$ & $1.43 \mathrm{E}-10$ & $2.24 \mathrm{E}-10$ \\
\hline $2.6 \ldots$ & $3.91 \mathrm{E}-12$ & $1.85 \mathrm{E}-11$ & $1.07 \mathrm{E}-10$ & $6.82 \mathrm{E}-11$ & $1.25 \mathrm{E}-10$ & $1.95 \mathrm{E}-10$ \\
\hline $2.7 \ldots \ldots$ & $3.39 \mathrm{E}-12$ & $1.61 \mathrm{E}-11$ & $8.69 \mathrm{E}-11$ & $5.91 \mathrm{E}-11$ & $1.09 \mathrm{E}-10$ & $1.70 \mathrm{E}-10$ \\
\hline $2.8 \ldots \ldots$ & $2.94 \mathrm{E}-12$ & $1.41 \mathrm{E}-11$ & $7.09 \mathrm{E}-11$ & $5.13 \mathrm{E}-11$ & $9.46 \mathrm{E}-11$ & $1.48 \mathrm{E}-10$ \\
\hline $2.9 \ldots$ & $2.55 \mathrm{E}-12$ & $1.26 \mathrm{E}-11$ & $5.86 \mathrm{E}-11$ & $4.45 \mathrm{E}-11$ & $8.22 \mathrm{E}-11$ & $1.29 \mathrm{E}-10$ \\
\hline $3.0 \ldots$ & $2.21 \mathrm{E}-12$ & $1.16 \mathrm{E}-11$ & $4.97 \mathrm{E}-11$ & $3.85 \mathrm{E}-11$ & $7.15 \mathrm{E}-11$ & $1.13 \mathrm{E}-10$ \\
\hline $3.1 \ldots \ldots$ & $1.91 \mathrm{E}-12$ & $1.12 \mathrm{E}-11$ & $4.37 \mathrm{E}-11$ & $3.33 \mathrm{E}-11$ & $6.21 \mathrm{E}-11$ & $9.80 \mathrm{E}-11$ \\
\hline $3.2 \ldots$ & $1.66 \mathrm{E}-12$ & $E-11$ & $E-11$ & $E-11$ & $E-11$ & $3 \mathrm{E}-11$ \\
\hline 3.3. & $1.44 \mathrm{E}-12$ & $E-11$ & $3.69 \mathrm{E}-11$ & $E-11$ & $E-11$ & $2 \mathrm{E}-11$ \\
\hline 3.4. & $1.26 \mathrm{E}-12$ & $1.12 \mathrm{E}-11$ & $3.43 \mathrm{E}-11$ & $2.16 \mathrm{E}-11$ & $4.05 \mathrm{E}-11$ & $6.44 \mathrm{E}-11$ \\
\hline $3.5 \ldots$ & $1.10 \mathrm{E}-12$ & $1.08 \mathrm{E}-11$ & $3.15 \mathrm{E}-11$ & $1.87 \mathrm{E}-11$ & $3.51 \mathrm{E}-11$ & $5.60 \mathrm{E}-11$ \\
\hline $3.6 \ldots$ & $9.72 \mathrm{E}-13$ & $E-11$ & $3 E-11$ & $1 \mathrm{E}-11$ & $3 E-11$ & $4.86 \mathrm{E}-11$ \\
\hline $3.7 \ldots$ & $8.67 \mathrm{E}-13$ & $9.03 \mathrm{E}-12$ & $E-11$ & $E-11$ & $2.63 \mathrm{E}-11$ & $4.21 \mathrm{E}-11$ \\
\hline $3.8 \ldots$ & $7.85 \mathrm{E}-13$ & $7.91 \mathrm{E}-12$ & $13 \mathrm{E}-11$ & $E-11$ & $2.27 \mathrm{E}-11$ & $3.65 \mathrm{E}-11$ \\
\hline $3.9 \ldots$ & $7.25 \mathrm{E}-13$ & $6.86 \mathrm{E}-12$ & $1.80 \mathrm{E}-11$ & $1.03 \mathrm{E}-11$ & $1.96 \mathrm{E}-11$ & $3.16 \mathrm{E}-11$ \\
\hline $4.0 \ldots$ & $6.90 \mathrm{E}-13$ & $6.02 \mathrm{E}-12$ & $1.53 \mathrm{E}-11$ & $8.83 \mathrm{E}-12$ & $1.69 \mathrm{E}-11$ & $2.73 \mathrm{E}-11$ \\
\hline $4.1 \ldots$ & $E-13$ & $E-12$ & -11 & -12 & $E-11$ & $6 \mathrm{E}-11$ \\
\hline 4.2. & $8.50 \mathrm{E}-13$ & $5.40 \mathrm{E}-12$ & $E-11$ & $6.44 \mathrm{E}-12$ & $E-11$ & $2.04 \mathrm{E}-11$ \\
\hline $4.3 .$. & $1.30 \mathrm{E}-12$ & $6.02 \mathrm{E}-12$ & $1.73 \mathrm{E}-11$ & $5.48 \mathrm{E}-12$ & $1.07 \mathrm{E}-11$ & $1.76 \mathrm{E}-11$ \\
\hline $4.4 .$. & $2.26 \mathrm{E}-12$ & $7.86 \mathrm{E}-12$ & $2.28 \mathrm{E}-11$ & $4.65 \mathrm{E}-12$ & $9.23 \mathrm{E}-12$ & $1.52 \mathrm{E}-11$ \\
\hline 4.5 . & $E-12$ & $E-11$ & $E-11$ & -12 & $E-12$ & $31 \mathrm{E}-11$ \\
\hline $4.6 \ldots$ & $5.90 \mathrm{E}-12$ & $E-11$ & $E-11$ & -12 & $E-12$ & $3 E-11$ \\
\hline $4.7 \ldots$ & $8.02 \mathrm{E}-12$ & & & $2.80 \mathrm{E}-12$ & $5.80 \mathrm{E}-12$ & $9.67 \mathrm{E}-12$ \\
\hline $4.8 \ldots \ldots$ & $9.72 \mathrm{E}-12$ & $2.62 \mathrm{E}-11$ & $3.79 \mathrm{E}-11$ & $2.35 \mathrm{E}-12$ & $4.95 \mathrm{E}-12$ & $8.30 \mathrm{E}-12$ \\
\hline $4.9 \ldots$ & $1.07 \mathrm{E}-11$ & $2.88 \mathrm{E}-11$ & $3.58 \mathrm{E}-11$ & $1.97 \mathrm{E}-12$ & $4.22 \mathrm{E}-12$ & $7.12 \mathrm{E}-12$ \\
\hline $5.0 \ldots$ & $1.08 \mathrm{E}-11$ & $2.91 \mathrm{E}-11$ & $3.20 \mathrm{E}-11$ & $E-12$ & $E-12$ & $6.09 \mathrm{E}-12$ \\
\hline $5.1 \ldots$ & $1.01 \mathrm{E}-11$ & $2.74 \mathrm{E}-11$ & $2.74 \mathrm{E}-11$ & $1.38 \mathrm{E}-12$ & $3.06 \mathrm{E}-12$ & $5.21 \mathrm{E}-12$ \\
\hline $5.2 \ldots$ & $9.03 \mathrm{E}-12$ & $2.45 \mathrm{E}-11$ & $2.27 \mathrm{E}-11$ & $1.14 \mathrm{E}-12$ & $2.60 \mathrm{E}-12$ & $4.45 \mathrm{E}-12$ \\
\hline $5.3 \ldots$ & $7.69 \mathrm{E}-12$ & $2.08 \mathrm{E}-11$ & $1.83 \mathrm{E}-11$ & $9.50 \mathrm{E}-13$ & $2.20 \mathrm{E}-12$ & $3.79 \mathrm{E}-12$ \\
\hline $5.4 \ldots$ & $E-12$ & $E-11$ & -11 & -13 & $E-12$ & $3.23 \mathrm{E}-12$ \\
\hline $5.5 \ldots$ & $.05 \mathrm{E}-12$ & $E-11$ & -11 & -13 & $1.57 \mathrm{E}-12$ & $2.74 \mathrm{E}-12$ \\
\hline $5.6 \ldots$ & $3.95 \mathrm{E}-12$ & $1.06 \mathrm{E}-11$ & $8.65 \mathrm{E}-12$ & $5.59 \mathrm{E}-13$ & $1.34 \mathrm{E}-12$ & $2.32 \mathrm{E}-12$ \\
\hline $5.7 \ldots \ldots$ & $3.04 \mathrm{E}-12$ & $8.14 \mathrm{E}-12$ & $6.56 \mathrm{E}-12$ & $5.41 \mathrm{E}-13$ & $1.19 \mathrm{E}-12$ & $1.96 \mathrm{E}-12$ \\
\hline $5.8 \ldots \ldots$ & $2.31 \mathrm{E}-12$ & $6.13 \mathrm{E}-12$ & -12 & $6.49 \mathrm{E}-13$ & $1.19 \mathrm{E}-12$ & $1.66 \mathrm{E}-12$ \\
\hline $5.9 \ldots$ & $.75 \mathrm{E}-12$ & -12 & -12 & $E-13$ & $1.42 \mathrm{E}-12$ & $1.40 \mathrm{E}-12$ \\
\hline $6.0 \ldots$ & $1.32 \mathrm{E}-12$ & $3.36 \mathrm{E}-12$ & $2.71 \mathrm{E}-12$ & $1.29 \mathrm{E}-12$ & $1.90 \mathrm{E}-12$ & $1.17 \mathrm{E}-12$ \\
\hline $6.1 \ldots$ & $9.93 \mathrm{E}-13$ & $2.46 \mathrm{E}-12$ & $1.99 \mathrm{E}-12$ & $1.68 \mathrm{E}-12$ & $2.53 \mathrm{E}-12$ & $9.81 \mathrm{E}-13$ \\
\hline 6.2. & $7.53 \mathrm{E}-13$ & $1.79 \mathrm{E}-12$ & $1.46 \mathrm{E}-12$ & $1.98 \mathrm{E}-12$ & $3.12 \mathrm{E}-12$ & $8.19 \mathrm{E}-13$ \\
\hline & $5.74 \mathrm{E}-13$ & $E-12$ & -12 & $3 E-12$ & $3.53 \mathrm{E}-12$ & $6.81 \mathrm{E}-13$ \\
\hline 6.4 . & $4.36 \mathrm{E}-13$ & -13 & $E-13$ & -12 & $3.67 \mathrm{E}-12$ & $5.64 \mathrm{E}-13$ \\
\hline $6.5 \ldots$ & $3.35 \mathrm{E}-13$ & $6.73 E-13$ & $5.60 \mathrm{E}-13$ & $1.96 \mathrm{E}-12$ & $3.54 \mathrm{E}-12$ & $4.65 \mathrm{E}-13$ \\
\hline $6.6 \ldots$. & $2.59 \mathrm{E}-13$ & $4.79 E-13$ & $4.07 E-13$ & $1.73 \mathrm{E}-12$ & $3.22 \mathrm{E}-12$ & $3.82 \mathrm{E}-13$ \\
\hline & $2.00 \mathrm{E}-13$ & $3.43 \mathrm{E}-13$ & $2.96 \mathrm{E}-13$ & $1.45 \mathrm{E}-12$ & $2.79 \mathrm{E}-12$ & $3.12 \mathrm{E}-13$ \\
\hline & $1.55 \mathrm{E}-13$ & $2.45 \mathrm{E}-13$ & $2.10 \mathrm{E}-13$ & -12 & $2.32 \mathrm{E}-12$ & $2.54 \mathrm{E}-13$ \\
\hline $6.9 .$. & $1.20 \mathrm{E}-13$ & $1.75 \mathrm{E}-13$ & $1.52 \mathrm{E}-13$ & $9.34 \mathrm{E}-13$ & $1.87 \mathrm{E}-12$ & $2.05 \mathrm{E}-13$ \\
\hline $7.0 \ldots$ & $9.28 \mathrm{E}-14$ & $1.25 \mathrm{E}-13$ & $1.10 \mathrm{E}-13$ & $7.22 \mathrm{E}-13$ & $1.47 \mathrm{E}-12$ & $1.65 \mathrm{E}-13$ \\
\hline $7.1 \ldots$ & $7.15 \mathrm{E}-14$ & $8.88 \mathrm{E}-14$ & $7.97 \mathrm{E}-14$ & $5.49 \mathrm{E}-13$ & $1.13 \mathrm{E}-12$ & $1.32 \mathrm{E}-13$ \\
\hline $7.2 \ldots$ & $5.49 \mathrm{E}-14$ & $6.33 \mathrm{E}-14$ & $5.78 \mathrm{E}-14$ & $4.12 \mathrm{E}-13$ & $8.59 \mathrm{E}-13$ & $1.05 \mathrm{E}-13$ \\
\hline $7.3 .$. & $4.20 \mathrm{E}-14$ & $4.51 \mathrm{E}-14$ & $4.19 \mathrm{E}-14$ & $3.05 \mathrm{E}-13$ & $6.43 \mathrm{E}-13$ & $8.25 \mathrm{E}-14$ \\
\hline $7.4 \ldots$. & $3.21 \mathrm{E}-14$ & $3.21 \mathrm{E}-14$ & $3.04 \mathrm{E}-14$ & $2.24 \mathrm{E}-13$ & $4.77 \mathrm{E}-13$ & $6.47 \mathrm{E}-14$ \\
\hline $7.5 \ldots$ & $2.44 \mathrm{E}-14$ & $2.29 \mathrm{E}-14$ & $2.21 \mathrm{E}-14$ & $1.64 \mathrm{E}-13$ & $3.51 \mathrm{E}-13$ & $5.05 \mathrm{E}-14$ \\
\hline $7.6 \ldots$ & $1.85 \mathrm{E}-14$ & $1.63 \mathrm{E}-14$ & $1.61 \mathrm{E}-14$ & $1.18 \mathrm{E}-13$ & $2.57 \mathrm{E}-13$ & $3.92 \mathrm{E}-14$ \\
\hline $7.7 \ldots$ & $1.39 \mathrm{E}-14$ & $1.16 \mathrm{E}-14$ & $1.17 \mathrm{E}-14$ & $8.51 \mathrm{E}-14$ & $1.87 \mathrm{E}-13$ & $3.01 \mathrm{E}-14$ \\
\hline & $1.05 \mathrm{E}-14$ & $8.28 \mathrm{E}-15$ & $8.48 \mathrm{E}-15$ & $6.13 E-14$ & $1.33 \mathrm{E}-13$ & $2.31 \mathrm{E}-14$ \\
\hline $7.9 \ldots$ & $7.89 \mathrm{E}-15$ & $5.91 \mathrm{E}-15$ & $6.17 \mathrm{E}-15$ & $4.40 \mathrm{E}-14$ & $9.64 \mathrm{E}-14$ & $1.76 \mathrm{E}-14$ \\
\hline $8.0 \ldots \ldots$ & $5.91 \mathrm{E}-15$ & $4.22 \mathrm{E}-15$ & $4.49 \mathrm{E}-15$ & $3.14 \mathrm{E}-14$ & $6.95 \mathrm{E}-14$ & $1.33 \mathrm{E}-14$ \\
\hline
\end{tabular}


TABLE 5-Continued

\begin{tabular}{|c|c|c|c|c|c|c|}
\hline \multirow[b]{2}{*}{$\log _{10} T$} & \multicolumn{6}{|c|}{$\alpha_{R}(T)$} \\
\hline & $\mathrm{C}_{\mathrm{I}}$ & $\mathrm{C}_{\text {II }}$ & $\mathrm{C}$ III & C IV & $\mathrm{C} \mathrm{v}$ & $\mathrm{C}$ VI \\
\hline 8.1. & $4.42 \mathrm{E}-15$ & $3.02 E-15$ & $3.27 E-15$ & $2.25 \mathrm{E}-14$ & $4.98 \mathrm{E}-14$ & $1.01 \mathrm{E}-14$ \\
\hline $8.2 \ldots \ldots$ & $3.30 \mathrm{E}-15$ & $2.16 \mathrm{E}-15$ & $2.39 \mathrm{E}-15$ & $1.61 \mathrm{E}-14$ & $3.57 \mathrm{E}-14$ & $7.56 \mathrm{E}-15$ \\
\hline $8.3 \ldots \ldots$ & $2.46 \mathrm{E}-15$ & $1.55 \mathrm{E}-15$ & $1.74 \mathrm{E}-15$ & $1.15 E-14$ & $2.56 \mathrm{E}-14$ & $5.65 \mathrm{E}-15$ \\
\hline $8.4 \ldots \ldots$ & $1.83 \mathrm{E}-15$ & $1.12 \mathrm{E}-15$ & $1.28 \mathrm{E}-15$ & $8.17 \mathrm{E}-15$ & $1.84 \mathrm{E}-14$ & $4.21 \mathrm{E}-15$ \\
\hline $8.5 \ldots \ldots$ & $1.36 \mathrm{E}-15$ & $8.05 \mathrm{E}-16$ & $9.36 \mathrm{E}-16$ & $5.82 \mathrm{E}-15$ & $1.32 \mathrm{E}-14$ & $3.12 \mathrm{E}-15$ \\
\hline $8.6 \ldots .$. & $1.01 \mathrm{E}-15$ & $5.83 \mathrm{E}-16$ & $6.89 \mathrm{E}-16$ & $4.15 E-15$ & $9.43 E-15$ & $2.30 \mathrm{E}-15$ \\
\hline $8.7 \ldots \ldots$ & $7.53 \mathrm{E}-16$ & $4.24 \mathrm{E}-16$ & $5.09 \mathrm{E}-16$ & $2.96 \mathrm{E}-15$ & $6.76 \mathrm{E}-15$ & $1.69 \mathrm{E}-15$ \\
\hline $8.8 \ldots \ldots$ & $5.60 \mathrm{E}-16$ & $3.10 \mathrm{E}-16$ & $3.77 \mathrm{E}-16$ & $2.11 \mathrm{E}-15$ & $4.84 \mathrm{E}-15$ & $1.24 \mathrm{E}-15$ \\
\hline $8.9 \ldots \ldots$ & $4.17 \mathrm{E}-16$ & $2.28 \mathrm{E}-16$ & $2.81 \mathrm{E}-16$ & $1.50 \mathrm{E}-15$ & $3.48 \mathrm{E}-15$ & $9.11 \mathrm{E}-16$ \\
\hline $9.0 \ldots \ldots$ & $3.10 \mathrm{E}-16$ & $1.69 E-16$ & $2.11 \mathrm{E}-16$ & $1.07 \mathrm{E}-15$ & $2.50 \mathrm{E}-15$ & $6.63 \mathrm{E}-16$ \\
\hline
\end{tabular}

Note.-Total recombination rate coefficients, $\alpha_{R}(T)$ (in units of $\mathrm{cm}^{3} \mathrm{~s}^{-1}$ ) for the carbon ions, $\mathrm{C}_{\mathrm{I}-\mathrm{C}} \mathrm{VI}$, in the temperature range of $1.0 \leq \log _{10}(T) \leq 9.0$.

used the hydrogenic photoionization code by Storey \& Hummer (1992) to compute the H-like data and have found nearly perfect agreement with their hydrogenic recombination rates in the low-density regime; thus, we expect the present data for $\mathrm{C}$ VI and $\mathrm{N}$ viI to be accurate. Tables 7 and 8 give the numerical values of the coronal ionization fractions.

\section{CONCLUDING REMARKS}

The two main data sets computed are the total photoionization cross sections and electron-ion recombination rate coefficients. The state-specific data may also be useful for specialized non-LTE calculations. The details of the atomic physics work have been discussed in several previous works cited. Here we discuss features relevant to the application of these data sets to astrophysical and laboratory plasmas. Ionization fractions in collisional equilibrium (coronal approximation) are also calculated to illustrate differences with previous works. We describe the computed data sets below.

1. The photoionization cross sections contain a considerable amount of structure, tabulated at a fine mesh in photon energy, which in the case of ionization by a radiation source can be readily averaged over. However, except in the idealized blackbody case, we do not recommend preaveraged fits over the cross sections, neglecting the correspondence between the autoionizing resonances and specific features of the radiation field, such as from a star of given spectral type. As only the total ground state photoionization cross sections are usually of interest in evaluating the left-hand side of equation (1), the users may wish to scan these cross sections prior to averaging. A simple test would be to obtain running averages of the following kind:

$$
\langle\sigma(E)\rangle=\frac{1}{\Delta E} \int_{E-\Delta E / 2}^{E+\Delta E / 2} \sigma(E) d E,
$$

with different $\Delta E$ values to ascertain the effect on the photoionization rates. We have found that it is sometimes necessary to take account of the broad near-threshold resonances explicitly. While the present total photoionization cross sections of the ground states are generally in good agreement with the OP data, such as in TOPbase (Cunto et al. 1993), there are differences in terms of slightly better accuracy, more resonance structure, and perhaps most importantly, complete consistency between the present photoionization and recombination data.
2. The total electron-ion recombination rates have a general pattern that is now well established (e.g., NP), as shown in Figures 7 and 8 for $\mathrm{C}$ and $\mathrm{N}$ ions. Starting with high values at low- $T$ dominated by recombination of lowenergy electrons into very high $n$ states, the $\alpha_{R}(T)$ decrease but may exhibit low- $T$ bump(s) due to recombinations via near-threshold autoionizing resonances. The $\alpha_{R}(T)$ reaches a minimum before being enhanced by high- $T$ DR of highenergy electrons, falling off toward still higher temperatures because of the Maxwellian factor.

3. The overall uncertainty in the electron-ion recombination data is estimated to be $10 \%-20 \%$, based on detailed comparison of photorecombination cross sections with experimentally measured values in storage rings and ion traps for several ions showing general agreement at that level or better. These calculations and comparisons are described by Nahar et al. (1997b) for electron recombination with C VI, O VII, and C v, and by Zhang \& Pradhan (1997) for Ar XIV and Fe XXv. Relativistic effects are also included theoretically, and it is found that for the lighter elements there is good agreement in overall magnitude of cross sections with the nonrelativistic results, although fine structure leads to more detailed features. The effect on rate coefficients, of primary concern herein, should be negligible.

4. The comparison of the present ionization fractions with the previous works shows good agreement in general. However, some significant differences are found in the peak values and near temperatures where rapid variations occur.

5. Photoionization and recombination work on oxygen ions, and some iron ions, is in progress.

All photoionization and recombination data are available electronically from the first author at nahar@payne.mps.ohio-state.edu. TOPbase may be accessed via Telnet as: (1) in the US, IP: 128.183.101.54 or topbase.gsfc.nasa.gov, login: topbase, pw: Seaton + ; (2) in Europe (at CDS), IP: 130.79.128.5, login: topbase, pw: Seaton + .

The work has been supported partially by NASA grants NAGW-3315 (LTSA) and NAS-32643, and NSF grant PHY-9421898. The computational work was carried out on the Cray Y-MP at the Ohio Supercomputer Center. 
TABLE 6

Total ReCombination Rate CoEFFicients FOR Nitrogen IONS

\begin{tabular}{|c|c|c|c|c|c|c|c|}
\hline \multirow[b]{2}{*}{$\log _{10} T$} & \multicolumn{7}{|c|}{$\alpha_{R}(T)$} \\
\hline & $\mathrm{N}_{\mathrm{I}}$ & $\mathrm{N}$ II & $\mathrm{N}$ III & $\mathrm{N}$ IV & $\mathrm{N} \mathrm{v}$ & N VI & N VII \\
\hline $1.0 .$. & $3.06 \mathrm{E}-11$ & $1.61 \mathrm{E}-10$ & $3.65 \mathrm{E}-10$ & $6.50 \mathrm{E}-10$ & $9.71 \mathrm{E}-10$ & $1.53 \mathrm{E}-09$ & $2.20 \mathrm{E}-09$ \\
\hline $1.1 \ldots$ & $2.66 \mathrm{E}-11$ & $1.41 \mathrm{E}-10$ & $3.20 \mathrm{E}-10$ & $5.71 \mathrm{E}-10$ & $8.54 \mathrm{E}-10$ & $1.35 \mathrm{E}-09$ & $1.94 \mathrm{E}-09$ \\
\hline $1.2 \ldots$ & $2.31 \mathrm{E}-11$ & $1.23 \mathrm{E}-10$ & $2.81 \mathrm{E}-10$ & $5.02 \mathrm{E}-10$ & $7.49 \mathrm{E}-10$ & $1.19 \mathrm{E}-09$ & $1.71 \mathrm{E}-09$ \\
\hline $1.3 \ldots$ & $2.01 \mathrm{E}-11$ & $1.08 \mathrm{E}-10$ & $2.46 \mathrm{E}-10$ & $4.40 \mathrm{E}-10$ & $6.58 \mathrm{E}-10$ & $1.05 \mathrm{E}-09$ & $1.51 \mathrm{E}-09$ \\
\hline $1.4 \ldots$ & $1.75 E-11$ & $9.43 \mathrm{E}-11$ & $2.15 \mathrm{E}-10$ & $3.86 \mathrm{E}-10$ & $5.77 \mathrm{E}-10$ & $9.21 \mathrm{E}-10$ & $1.33 \mathrm{E}-09$ \\
\hline $1.5 \ldots$ & $1.52 \mathrm{E}-11$ & $8.24 \mathrm{E}-11$ & $1.88 \mathrm{E}-10$ & $3.38 \mathrm{E}-10$ & $5.06 \mathrm{E}-10$ & $8.09 \mathrm{E}-10$ & $1.17 \mathrm{E}-09$ \\
\hline $1.6 \ldots$ & $1.32 \mathrm{E}-11$ & $7.20 \mathrm{E}-11$ & $1.65 \mathrm{E}-10$ & $2.96 \mathrm{E}-10$ & $4.43 E-10$ & $7.10 \mathrm{E}-10$ & $1.03 \mathrm{E}-09$ \\
\hline $1.7 \ldots$ & $1.14 \mathrm{E}-11$ & $6.29 \mathrm{E}-11$ & $1.44 \mathrm{E}-10$ & $2.59 \mathrm{E}-10$ & $3.87 \mathrm{E}-10$ & $6.23 \mathrm{E}-10$ & $9.02 \mathrm{E}-10$ \\
\hline $1.8 \ldots$ & $9.87 \mathrm{E}-12$ & $5.49 \mathrm{E}-11$ & $1.26 \mathrm{E}-10$ & $2.26 \mathrm{E}-10$ & $3.38 \mathrm{E}-10$ & $5.46 \mathrm{E}-10$ & $7.94 \mathrm{E}-10$ \\
\hline $1.9 \ldots$ & $8.54 \mathrm{E}-12$ & $4.80 \mathrm{E}-11$ & $1.10 \mathrm{E}-10$ & $1.98 \mathrm{E}-10$ & $2.96 \mathrm{E}-10$ & $4.78 \mathrm{E}-10$ & $6.95 \mathrm{E}-10$ \\
\hline 2.0 .. & $7.38 \mathrm{E}-12$ & $4.18 \mathrm{E}-11$ & $9.59 \mathrm{E}-11$ & $1.73 \mathrm{E}-10$ & $2.58 \mathrm{E}-10$ & $4.18 \mathrm{E}-10$ & $6.10 \mathrm{E}-10$ \\
\hline $2.1 \ldots$ & $6.38 \mathrm{E}-12$ & $3.64 \mathrm{E}-11$ & $8.36 \mathrm{E}-11$ & $1.51 \mathrm{E}-10$ & $2.25 \mathrm{E}-10$ & $3.66 \mathrm{E}-10$ & $5.34 \mathrm{E}-10$ \\
\hline $2.2 \ldots$ & $5.50 \mathrm{E}-12$ & $3.17 \mathrm{E}-11$ & $7.29 \mathrm{E}-11$ & $1.31 \mathrm{E}-10$ & $1.96 \mathrm{E}-10$ & $3.20 \mathrm{E}-10$ & $4.68 \mathrm{E}-10$ \\
\hline $2.3 \ldots$ & $4.75 \mathrm{E}-12$ & $2.77 \mathrm{E}-11$ & $6.36 \mathrm{E}-11$ & $1.15 \mathrm{E}-10$ & $1.71 \mathrm{E}-10$ & $2.79 \mathrm{E}-10$ & $4.09 \mathrm{E}-10$ \\
\hline $2.4 \ldots$ & $4.09 \mathrm{E}-12$ & $2.41 \mathrm{E}-11$ & $5.54 \mathrm{E}-11$ & $9.98 \mathrm{E}-11$ & $1.49 \mathrm{E}-10$ & $2.44 \mathrm{E}-10$ & $3.58 \mathrm{E}-10$ \\
\hline $2.5 \ldots$ & $3.54 \mathrm{E}-12$ & $2.09 \mathrm{E}-11$ & $4.85 \mathrm{E}-11$ & $8.72 \mathrm{E}-11$ & $1.29 \mathrm{E}-10$ & $2.13 \mathrm{E}-10$ & $3.13 \mathrm{E}-10$ \\
\hline $2.6 \ldots$ & $3.07 \mathrm{E}-12$ & $1.82 \mathrm{E}-11$ & $4.28 \mathrm{E}-11$ & $7.63 \mathrm{E}-11$ & $1.12 \mathrm{E}-10$ & $1.85 \mathrm{E}-10$ & $2.73 \mathrm{E}-10$ \\
\hline $2.7 .$. & $2.69 \mathrm{E}-12$ & $1.58 \mathrm{E}-11$ & $3.84 \mathrm{E}-11$ & $6.72 \mathrm{E}-11$ & $9.76 \mathrm{E}-11$ & $1.62 \mathrm{E}-10$ & $2.38 \mathrm{E}-10$ \\
\hline $2.8 .$. & $2.37 \mathrm{E}-12$ & $1.38 \mathrm{E}-11$ & $3.53 \mathrm{E}-11$ & $5.99 \mathrm{E}-11$ & $8.47 \mathrm{E}-11$ & $1.41 \mathrm{E}-10$ & $2.08 \mathrm{E}-10$ \\
\hline $2.9 .$. & $2.11 \mathrm{E}-12$ & $1.20 \mathrm{E}-11$ & $3.32 \mathrm{E}-11$ & $5.39 \mathrm{E}-11$ & $7.34 \mathrm{E}-11$ & $1.22 \mathrm{E}-10$ & $1.81 \mathrm{E}-10$ \\
\hline $3.0 \ldots$ & $1.89 \mathrm{E}-12$ & $1.04 \mathrm{E}-11$ & $3.16 \mathrm{E}-11$ & $4.90 \mathrm{E}-11$ & $6.37 \mathrm{E}-11$ & $1.06 \mathrm{E}-10$ & $1.58 \mathrm{E}-10$ \\
\hline $3.1 \ldots \ldots$ & $1.69 \mathrm{E}-12$ & $9.02 \mathrm{E}-12$ & $3.00 \mathrm{E}-11$ & $4.45 \mathrm{E}-11$ & $5.52 \mathrm{E}-11$ & $9.26 \mathrm{E}-11$ & $1.38 \mathrm{E}-10$ \\
\hline 3.2. & $1.50 \mathrm{E}-12$ & $7.84 \mathrm{E}-12$ & $2.83 \mathrm{E}-11$ & $4.05 E-11$ & $4.78 \mathrm{E}-11$ & $8.04 \mathrm{E}-11$ & $1.20 \mathrm{E}-10$ \\
\hline $3.3 .$. & $1.34 \mathrm{E}-12$ & $6.83 \mathrm{E}-12$ & $2.65 \mathrm{E}-11$ & $3.70 \mathrm{E}-11$ & $4.13 \mathrm{E}-11$ & $6.98 \mathrm{E}-11$ & $1.04 \mathrm{E}-10$ \\
\hline $3.4 \ldots$ & $1.19 \mathrm{E}-12$ & $5.98 \mathrm{E}-12$ & $2.47 \mathrm{E}-11$ & $3.40 \mathrm{E}-11$ & $3.58 \mathrm{E}-11$ & $6.06 \mathrm{E}-11$ & $9.07 \mathrm{E}-11$ \\
\hline $3.5 \ldots \ldots$ & $1.05 \mathrm{E}-12$ & $5.27 \mathrm{E}-12$ & $2.29 \mathrm{E}-11$ & $3.18 \mathrm{E}-11$ & $3.09 \mathrm{E}-11$ & $5.25 \mathrm{E}-11$ & $7.89 \mathrm{E}-11$ \\
\hline $3.6 \ldots$ & $9.26 \mathrm{E}-13$ & $4.69 \mathrm{E}-12$ & $2.10 \mathrm{E}-11$ & $3.00 \mathrm{E}-11$ & $2.66 \mathrm{E}-11$ & $4.55 \mathrm{E}-11$ & $6.85 \mathrm{E}-11$ \\
\hline $3.7 .$. & $8.10 \mathrm{E}-13$ & $4.21 \mathrm{E}-12$ & $1.91 \mathrm{E}-11$ & $2.86 \mathrm{E}-11$ & $2.30 \mathrm{E}-11$ & $3.94 \mathrm{E}-11$ & $5.95 \mathrm{E}-11$ \\
\hline $3.8 .$. & $7.05 \mathrm{E}-13$ & $3.79 \mathrm{E}-12$ & $1.73 \mathrm{E}-11$ & $2.70 \mathrm{E}-11$ & $1.98 \mathrm{E}-11$ & $3.40 \mathrm{E}-11$ & $5.16 \mathrm{E}-11$ \\
\hline $3.9 \ldots$ & $6.11 \mathrm{E}-13$ & $3.42 \mathrm{E}-12$ & $1.58 \mathrm{E}-11$ & $2.51 \mathrm{E}-11$ & $1.70 \mathrm{E}-11$ & $2.94 \mathrm{E}-11$ & $4.46 \mathrm{E}-11$ \\
\hline $4.0 \ldots \ldots$ & $5.28 \mathrm{E}-13$ & $8 E-12$ & $E-11$ & $\mathrm{E}-11$ & $6 E-11$ & $4 \mathrm{E}-11$ & $38 \mathrm{E}-11$ \\
\hline & $4.62 \mathrm{E}-13$ & $2.77 \mathrm{E}-12$ & $E-11$ & $2.08 \mathrm{E}-11$ & $5 E-11$ & $9 \mathrm{E}-11$ & $3.35 \mathrm{E}-11$ \\
\hline 4.2 . & $4.32 \mathrm{E}-13$ & $2.54 \mathrm{E}-12$ & $1.27 \mathrm{E}-11$ & $1.96 \mathrm{E}-11$ & $1.07 \mathrm{E}-11$ & $1.89 \mathrm{E}-11$ & $2.90 \mathrm{E}-11$ \\
\hline $4.3 \ldots$ & $4.93 E-13$ & $2.49 \mathrm{E}-12$ & $1.19 \mathrm{E}-11$ & $2.05 \mathrm{E}-11$ & $9.14 \mathrm{E}-12$ & $1.63 \mathrm{E}-11$ & $2.50 \mathrm{E}-11$ \\
\hline $4.4 \ldots$ & $7.40 \mathrm{E}-13$ & $2.90 \mathrm{E}-12$ & $1.18 \mathrm{E}-11$ & $2.45 \mathrm{E}-11$ & $7.79 \mathrm{E}-12$ & $1.40 \mathrm{E}-11$ & $2.16 \mathrm{E}-11$ \\
\hline $4.5 \ldots$ & $1.27 \mathrm{E}-12$ & $4.20 \mathrm{E}-12$ & $1.32 \mathrm{E}-11$ & $3.12 \mathrm{E}-11$ & $6.62 \mathrm{E}-12$ & $1.20 \mathrm{E}-11$ & $1.86 \mathrm{E}-11$ \\
\hline $4.6 \ldots \ldots$ & $2.11 \mathrm{E}-12$ & $6.73 \mathrm{E}-12$ & $1.69 \mathrm{E}-11$ & $3.88 \mathrm{E}-11$ & $5.61 \mathrm{E}-12$ & $1.03 \mathrm{E}-11$ & $1.61 \mathrm{E}-11$ \\
\hline 4.7. & $3.16 \mathrm{E}-12$ & $1.04 \mathrm{E}-11$ & $2.28 \mathrm{E}-11$ & $4.52 \mathrm{E}-11$ & $4.76 \mathrm{E}-12$ & $8.82 \mathrm{E}-12$ & $1.38 \mathrm{E}-11$ \\
\hline 4.8 . & $4.22 \mathrm{E}-12$ & $1.45 \mathrm{E}-11$ & $2.96 \mathrm{E}-11$ & $4.86 \mathrm{E}-11$ & $4.02 \mathrm{E}-12$ & $7.55 \mathrm{E}-12$ & $1.19 \mathrm{E}-11$ \\
\hline 4.9 . & $5.07 \mathrm{E}-12$ & $E-11$ & $E-11$ & -11 & $E-12$ & $E-12$ & $2 E-11$ \\
\hline 5.0 . & $5.55 \mathrm{E}-12$ & $2.05 \mathrm{E}-11$ & $3.89 \mathrm{E}-11$ & $E-11$ & $5 E-12$ & $\mathrm{OE}-12$ & $8.76 \mathrm{E}-12$ \\
\hline $5.1 .$. & $5.60 \mathrm{E}-12$ & $2.11 \mathrm{E}-11$ & $3.94 \mathrm{E}-11$ & $4.03 \mathrm{E}-11$ & $2.39 \mathrm{E}-12$ & $4.69 \mathrm{E}-12$ & $7.49 \mathrm{E}-12$ \\
\hline $5.2 .$. & $5.29 \mathrm{E}-12$ & $2.03 \mathrm{E}-11$ & $3.73 \mathrm{E}-11$ & $3.44 \mathrm{E}-11$ & $2.00 \mathrm{E}-12$ & $3.99 \mathrm{E}-12$ & $6.41 \mathrm{E}-12$ \\
\hline 5.3. & $4.72 \mathrm{E}-12$ & $1.83 \mathrm{E}-11$ & $3.34 \mathrm{E}-11$ & $2.85 \mathrm{E}-11$ & $1.67 \mathrm{E}-12$ & $3.39 \mathrm{E}-12$ & $5.48 \mathrm{E}-12$ \\
\hline $5.4 .$. & $.04 \mathrm{E}-12$ & $57 E-11$ & $2.85 \mathrm{E}-11$ & $E-11$ & $9 \mathrm{E}-12$ & $\mathrm{E}-12$ & $4.67 \mathrm{E}-12$ \\
\hline $5.5 \ldots$ & $3.33 \mathrm{E}-12$ & $1.30 \mathrm{E}-11$ & $2.35 \mathrm{E}-11$ & $1.82 \mathrm{E}-11$ & $1.15 \mathrm{E}-12$ & $2.43 \mathrm{E}-12$ & $3.98 \mathrm{E}-12$ \\
\hline 5.6. & $2.66 \mathrm{E}-12$ & $1.04 \mathrm{E}-11$ & $1.88 \mathrm{E}-11$ & $1.42 \mathrm{E}-11$ & $9.54 \mathrm{E}-13$ & $2.05 \mathrm{E}-12$ & $3.38 \mathrm{E}-12$ \\
\hline $5.7 .$. & $2.08 \mathrm{E}-12$ & $8.17 \mathrm{E}-12$ & $1.47 \mathrm{E}-11$ & $1.10 \mathrm{E}-11$ & $7.97 \mathrm{E}-13$ & $1.73 \mathrm{E}-12$ & $2.87 \mathrm{E}-12$ \\
\hline $5.8 .$. & $1.60 \mathrm{E}-12$ & -12 & $E-11$ & -12 & $E-13$ & $E-12$ & $2.43 \mathrm{E}-12$ \\
\hline 5.9 . & $1.21 \mathrm{E}-12$ & $4.72 \mathrm{E}-12$ & $8.53 \mathrm{E}-12$ & $6.30 \mathrm{E}-12$ & $7.11 \mathrm{E}-13$ & $1.31 \mathrm{E}-12$ & $2.05 \mathrm{E}-12$ \\
\hline 6.0 . & $9.01 \mathrm{E}-13$ & $3.52 \mathrm{E}-12$ & $6.36 \mathrm{E}-12$ & $4.72 \mathrm{E}-12$ & $8.68 \mathrm{E}-13$ & $1.29 \mathrm{E}-12$ & $1.73 E-12$ \\
\hline 6.1. & $6.68 \mathrm{E}-13$ & $2.59 \mathrm{E}-12$ & $4.70 \mathrm{E}-12$ & $3.51 \mathrm{E}-12$ & $1.17 \mathrm{E}-12$ & $1.45 \mathrm{E}-12$ & $1.45 \mathrm{E}-12$ \\
\hline 6.2. & $4.91 \mathrm{E}-13$ & $1.90 \mathrm{E}-12$ & $3.45 \mathrm{E}-12$ & $2.59 \mathrm{E}-12$ & $1.54 \mathrm{E}-12$ & $1.79 \mathrm{E}-12$ & $1.22 \mathrm{E}-12$ \\
\hline $6.3 .$. & $3.60 \mathrm{E}-13$ & -12 & $2.52 \mathrm{E}-12$ & $E-12$ & $E-12$ & $2.19 \mathrm{E}-12$ & $1.02 \mathrm{E}-12$ \\
\hline $6.4 \ldots$ & $2.57 \mathrm{E}-13$ & $1.00 \mathrm{E}-12$ & $1.83 \mathrm{E}-12$ & $1.40 \mathrm{E}-12$ & $2.08 \mathrm{E}-12$ & $2.53 \mathrm{E}-12$ & $8.46 \mathrm{E}-13$ \\
\hline $6.5 \ldots$ & $1.86 \mathrm{E}-13$ & $7.16 \mathrm{E}-13$ & $1.32 \mathrm{E}-12$ & $1.02 \mathrm{E}-12$ & $2.13 \mathrm{E}-12$ & $2.72 \mathrm{E}-12$ & $7.02 \mathrm{E}-13$ \\
\hline $6.6 \ldots \ldots$ & $1.34 \mathrm{E}-13$ & $5.14 \mathrm{E}-13$ & $9.55 \mathrm{E}-13$ & $7.47 \mathrm{E}-13$ & $2.04 \mathrm{E}-12$ & $2.72 \mathrm{E}-12$ & $5.80 \mathrm{E}-13$ \\
\hline $6.7 \ldots$ & $9.64 \mathrm{E}-14$ & $3.69 \mathrm{E}-13$ & $6.88 \mathrm{E}-13$ & $5.46 \mathrm{E}-13$ & $1.83 \mathrm{E}-12$ & $2.56 \mathrm{E}-12$ & $4.77 \mathrm{E}-13$ \\
\hline 6.8. & $6.93 \mathrm{E}-14$ & $2.64 \mathrm{E}-13$ & $4.88 \mathrm{E}-13$ & $4.00 \mathrm{E}-13$ & $1.57 \mathrm{E}-12$ & $2.27 \mathrm{E}-12$ & $3.91 \mathrm{E}-13$ \\
\hline 6.9. & $4.98 \mathrm{E}-14$ & $1.88 \mathrm{E}-13$ & $3.50 \mathrm{E}-13$ & $2.93 \mathrm{E}-13$ & $1.30 \mathrm{E}-12$ & $1.94 \mathrm{E}-12$ & $3.17 \mathrm{E}-13$ \\
\hline $7.0 \ldots \ldots$ & $3.57 \mathrm{E}-14$ & $1.34 \mathrm{E}-13$ & $2.51 \mathrm{E}-13$ & $2.09 \mathrm{E}-13$ & $1.04 \mathrm{E}-12$ & $1.60 \mathrm{E}-12$ & $2.58 \mathrm{E}-13$ \\
\hline & $2.56 \mathrm{E}-14$ & $9.59 \mathrm{E}-14$ & $1.79 \mathrm{E}-13$ & $1.53 \mathrm{E}-13$ & $8.14 \mathrm{E}-13$ & $1.27 \mathrm{E}-12$ & $2.07 \mathrm{E}-13$ \\
\hline $7.2 \ldots$ & $1.83 \mathrm{E}-14$ & $6.84 \mathrm{E}-14$ & $1.28 \mathrm{E}-13$ & $1.12 \mathrm{E}-13$ & $6.24 \mathrm{E}-13$ & $9.95 \mathrm{E}-13$ & $1.66 \mathrm{E}-13$ \\
\hline $7.3 \ldots$ & $1.32 \mathrm{E}-14$ & $4.87 \mathrm{E}-14$ & $9.13 \mathrm{E}-14$ & $8.19 \mathrm{E}-14$ & $4.72 \mathrm{E}-13$ & $7.64 \mathrm{E}-13$ & $1.32 \mathrm{E}-13$ \\
\hline $7.4 \ldots \ldots$ & $9.43 E-15$ & $3.47 \mathrm{E}-14$ & $6.53 \mathrm{E}-14$ & $6.00 \mathrm{E}-14$ & $3.52 \mathrm{E}-13$ & $5.78 \mathrm{E}-13$ & $1.04 \mathrm{E}-13$ \\
\hline $7.5 \ldots \ldots$ & $6.77 \mathrm{E}-15$ & $2.47 \mathrm{E}-14$ & $4.66 \mathrm{E}-14$ & $4.40 \mathrm{E}-14$ & $2.61 \mathrm{E}-13$ & $4.33 \mathrm{E}-13$ & $8.21 \mathrm{E}-14$ \\
\hline $7.6 \ldots \ldots$ & $4.86 \mathrm{E}-15$ & $1.76 \mathrm{E}-14$ & $3.33 E-14$ & $3.23 \mathrm{E}-14$ & $1.91 \mathrm{E}-13$ & $3.21 \mathrm{E}-13$ & $6.41 \mathrm{E}-14$ \\
\hline $7.7 \ldots$ & $3.50 \mathrm{E}-15$ & $1.26 \mathrm{E}-14$ & $2.38 \mathrm{E}-14$ & $2.37 \mathrm{E}-14$ & $1.40 \mathrm{E}-13$ & $2.37 \mathrm{E}-13$ & $4.99 \mathrm{E}-14$ \\
\hline $7.8 \ldots \ldots$ & $2.52 \mathrm{E}-15$ & $8.97 \mathrm{E}-15$ & $1.70 \mathrm{E}-14$ & $1.74 \mathrm{E}-14$ & $1.00 \mathrm{E}-13$ & $1.74 \mathrm{E}-13$ & $3.85 \mathrm{E}-14$ \\
\hline $7.9 \ldots \ldots$ & $1.82 \mathrm{E}-15$ & $6.40 \mathrm{E}-15$ & $1.22 \mathrm{E}-14$ & $1.28 \mathrm{E}-14$ & $7.27 \mathrm{E}-14$ & $1.24 \mathrm{E}-13$ & $2.95 \mathrm{E}-14$ \\
\hline $8.0 \ldots \ldots$ & $1.31 \mathrm{E}-15$ & $4.57 \mathrm{E}-15$ & $8.71 \mathrm{E}-15$ & $9.40 \mathrm{E}-15$ & $5.25 \mathrm{E}-14$ & $9.00 \mathrm{E}-14$ & $2.26 \mathrm{E}-14$ \\
\hline
\end{tabular}


TABLE 6-Continued

\begin{tabular}{|c|c|c|c|c|c|c|c|}
\hline \multirow[b]{2}{*}{$\log _{10} T$} & \multicolumn{7}{|c|}{$\alpha_{R}(T)$} \\
\hline & $\mathrm{N}_{\mathrm{I}}$ & $\mathrm{N}$ II & $\mathrm{N}$ III & $\mathrm{N}$ IV & $\mathrm{N} v$ & N vI & $\mathrm{N}$ VII \\
\hline $8.1 .$. & $9.54 \mathrm{E}-16$ & $3.27 \mathrm{E}-15$ & $6.24 \mathrm{E}-15$ & $6.91 \mathrm{E}-15$ & $3.77 \mathrm{E}-14$ & $6.52 \mathrm{E}-14$ & $1.71 \mathrm{E}-14$ \\
\hline $8.2 \ldots \ldots$ & $6.95 \mathrm{E}-16$ & $2.34 \mathrm{E}-15$ & $4.48 \mathrm{E}-15$ & $5.08 \mathrm{E}-15$ & $2.71 \mathrm{E}-14$ & $4.69 \mathrm{E}-14$ & $1.29 \mathrm{E}-14$ \\
\hline $8.3 \ldots$ & $5.09 \mathrm{E}-16$ & $1.68 \mathrm{E}-15$ & $3.22 \mathrm{E}-15$ & $3.73 E-15$ & $1.95 \mathrm{E}-14$ & $3.38 \mathrm{E}-14$ & $9.73 E-15$ \\
\hline $8.4 \ldots \ldots$ & $3.75 \mathrm{E}-16$ & $1.21 \mathrm{E}-15$ & $2.32 \mathrm{E}-15$ & $2.75 \mathrm{E}-15$ & $1.40 \mathrm{E}-14$ & $2.44 \mathrm{E}-14$ & $7.28 \mathrm{E}-15$ \\
\hline $8.5 \ldots$ & $2.78 \mathrm{E}-16$ & $8.73 \mathrm{E}-16$ & $1.67 \mathrm{E}-15$ & $2.03 E-15$ & $1.00 \mathrm{E}-14$ & $1.76 \mathrm{E}-14$ & $5.43 \mathrm{E}-15$ \\
\hline $8.6 \ldots \ldots$ & $2.07 \mathrm{E}-16$ & $6.33 \mathrm{E}-16$ & $1.21 \mathrm{E}-15$ & $1.50 \mathrm{E}-15$ & $7.16 \mathrm{E}-15$ & $1.27 \mathrm{E}-14$ & $4.03 E-15$ \\
\hline $8.7 \ldots \ldots$ & $1.56 \mathrm{E}-16$ & $4.60 \mathrm{E}-16$ & $8.82 \mathrm{E}-16$ & $1.11 \mathrm{E}-15$ & $5.13 \mathrm{E}-15$ & $9.11 \mathrm{E}-15$ & $2.98 \mathrm{E}-15$ \\
\hline $8.8 \ldots \ldots$ & $1.19 \mathrm{E}-16$ & $3.36 \mathrm{E}-16$ & $6.44 \mathrm{E}-16$ & $8.21 \mathrm{E}-16$ & $3.68 \mathrm{E}-15$ & $6.56 \mathrm{E}-15$ & $2.20 \mathrm{E}-15$ \\
\hline $8.9 \ldots \ldots$ & $9.14 \mathrm{E}-17$ & $2.48 \mathrm{E}-16$ & $4.73 \mathrm{E}-16$ & $6.11 \mathrm{E}-16$ & $2.64 \mathrm{E}-15$ & $4.73 \mathrm{E}-15$ & $1.61 \mathrm{E}-15$ \\
\hline $9.0 \ldots \ldots$ & $7.11 \mathrm{E}-17$ & $1.83 \mathrm{E}-16$ & $3.49 \mathrm{E}-16$ & $4.56 \mathrm{E}-16$ & $1.89 \mathrm{E}-15$ & $3.41 \mathrm{E}-15$ & $1.18 \mathrm{E}-15$ \\
\hline
\end{tabular}

NoTE.-Total recombination rate coefficients, $\alpha_{R}(T)$ (in units of $\mathrm{cm}^{3} \mathrm{~s}^{-1}$ ) for the nitrogen ions, $\mathrm{N} \mathrm{I}-\mathrm{N}$ vII, in the temperature range of $1.0 \leq \log _{10}(T) \leq 9.0$.

TABLE 7

IONIZATION Fractions OF CARbON IONS

\begin{tabular}{|c|c|c|c|c|c|c|c|}
\hline \multirow[b]{2}{*}{$\log _{10} T$} & \multicolumn{7}{|c|}{$N\left(X^{n+}\right) / N(X)$} \\
\hline & $\mathrm{C}_{\mathrm{I}}$ & C II & C III & $\mathrm{C}$ IV & $\mathrm{C} \mathrm{v}$ & C VI & C VII \\
\hline $3.5 \ldots \ldots$ & $\cdots$ & $\cdots$ & $\cdots$ & $\cdots$ & $\cdots$ & $\cdots$ & $\cdots$ \\
\hline $3.6 \ldots \ldots$ & & & $\ldots$ & $\ldots$ & $\ldots$ & $\ldots$ & $\ldots$ \\
\hline $3.7 \ldots \ldots$ & 0.00 & 7.50 & $\ldots$ & $\ldots$ & $\ldots$ & $\ldots$ & $\ldots$ \\
\hline $3.8 \ldots \ldots$ & 0.00 & 5.07 & $\ldots$ & $\ldots$ & $\ldots$ & $\ldots$ & $\ldots$ \\
\hline $3.9 \ldots \ldots$ & 0.00 & 3.12 & $\ldots$ & $\ldots$ & $\ldots$ & $\ldots$ & $\ldots$ \\
\hline $4.0 \ldots \ldots$ & 0.01 & 1.57 & & $\ldots$ & $\ldots$ & $\ldots$ & $\ldots$ \\
\hline $4.1 \ldots \ldots$ & 0.17 & 0.50 & 7.01 & $\ldots$ & $\ldots$ & $\ldots$ & $\ldots$ \\
\hline $4.2 \ldots \ldots$ & 0.69 & 0.10 & 4.56 & $\ldots$ & $\ldots$ & $\ldots$ & $\ldots$ \\
\hline $4.3 \ldots \ldots$ & 1.25 & 0.03 & 2.90 & $\ldots$ & $\ldots$ & $\ldots$ & $\ldots$ \\
\hline $4.4 \ldots \ldots$ & 1.66 & 0.02 & 1.70 & 9.20 & $\ldots$ & $\ldots$ & $\ldots$ \\
\hline $4.5 \ldots \ldots$ & 2.03 & 0.07 & 0.86 & 6.46 & $\ldots$ & $\ldots$ & $\ldots$ \\
\hline $4.6 \ldots \ldots$ & 2.47 & 0.25 & 0.36 & 4.42 & $\ldots$ & $\ldots$ & $\ldots$ \\
\hline $4.7 \ldots \ldots$ & 3.03 & 0.57 & 0.14 & 2.94 & 7.05 & $\ldots$ & $\ldots$ \\
\hline $4.8 \ldots \ldots$ & 3.63 & 0.95 & 0.06 & 1.83 & 4.46 & $\ldots$ & $\ldots$ \\
\hline $4.9 \ldots \ldots$ & 4.25 & 1.35 & 0.07 & 0.98 & 2.42 & $\ldots$ & $\ldots$ \\
\hline $5.0 \ldots \ldots$ & 5.01 & 1.90 & 0.27 & 0.47 & 0.93 & $\ldots$ & $\ldots$ \\
\hline $5.1 \ldots \ldots$ & 6.21 & 2.90 & 0.96 & 0.55 & 0.22 & $\ldots$ & $\ldots$ \\
\hline $5.2 \ldots \ldots$ & 7.69 & 4.18 & 1.96 & 1.04 & 0.05 & $\ldots$ & $\ldots$ \\
\hline $5.3 \ldots \ldots$ & 9.09 & 5.39 & 2.91 & 1.55 & 0.01 & 8.39 & $\ldots$ \\
\hline $5.4 \ldots \ldots$ & $\ldots$ & 6.46 & 3.74 & 1.99 & 0.00 & 6.23 & $\ldots$ \\
\hline $5.5 \ldots \ldots$ & $\ldots$ & 7.39 & 4.45 & 2.37 & 0.00 & 4.49 & $\ldots$ \\
\hline $5.6 \ldots \ldots$ & $\ldots$ & 8.21 & 5.06 & 2.68 & 0.00 & 3.07 & 7.85 \\
\hline $5.7 \ldots \ldots$ & $\ldots$ & 8.89 & 5.54 & 2.89 & 0.01 & 1.94 & 5.33 \\
\hline $5.8 \ldots \ldots$ & $\ldots$ & 9.44 & 5.89 & 3.00 & 0.04 & 1.10 & 3.35 \\
\hline $5.9 \ldots \ldots$ & $\ldots$ & 9.93 & 6.21 & 3.09 & 0.14 & 0.57 & 1.90 \\
\hline $6.0 \ldots \ldots$ & $\ldots$ & $\ldots$ & 6.59 & 3.27 & 0.37 & 0.34 & 0.93 \\
\hline $6.1 \ldots \ldots$ & $\ldots$ & $\ldots$ & 7.16 & 3.65 & 0.77 & 0.40 & 0.36 \\
\hline $6.2 \ldots \ldots$ & $\ldots$ & $\ldots$ & 7.91 & 4.22 & 1.34 & 0.68 & 0.13 \\
\hline $6.3 \ldots \ldots$ & $\ldots$ & $\ldots$ & 8.72 & 4.86 & 1.95 & 1.04 & 0.05 \\
\hline $6.4 \ldots \ldots$ & $\ldots$ & $\ldots$ & 9.51 & 5.48 & 2.52 & 1.37 & 0.02 \\
\hline $6.5 \ldots \ldots$ & $\ldots$ & $\ldots$ & $\ldots$ & 6.08 & 3.04 & 1.68 & 0.01 \\
\hline $6.6 \ldots \ldots$ & $\ldots$ & $\ldots$ & $\ldots$ & 6.64 & 3.51 & 1.94 & 0.01 \\
\hline $6.7 \ldots \ldots$ & $\ldots$ & $\ldots$ & $\ldots$ & 7.17 & 3.94 & 2.17 & $\ldots$ \\
\hline $6.8 \ldots \ldots$ & $\ldots$ & $\ldots$ & $\ldots$ & 7.67 & 4.34 & 2.38 & $\ldots$ \\
\hline $6.9 \ldots \ldots$ & $\ldots$ & $\ldots$ & $\ldots$ & 8.15 & 4.70 & 2.56 & $\ldots$ \\
\hline $7.0 \ldots \ldots$ & $\ldots$ & $\ldots$ & $\ldots$ & 8.61 & 5.05 & 2.73 & $\ldots$ \\
\hline $7.1 \ldots \ldots$ & $\ldots$ & $\ldots$ & $\ldots$ & 9.05 & 5.37 & 2.89 & $\ldots$ \\
\hline $7.2 \ldots \ldots$ & $\ldots$ & $\ldots$ & $\ldots$ & 9.48 & 5.67 & 3.03 & $\ldots$ \\
\hline $7.3 \ldots \ldots$ & $\ldots$ & $\ldots$ & $\ldots$ & 9.89 & 5.96 & 3.16 & $\ldots$ \\
\hline $7.4 \ldots \ldots$ & $\ldots$ & $\ldots$ & $\ldots$ & $\ldots$ & 6.24 & 3.29 & $\ldots$ \\
\hline
\end{tabular}

Note.-Ionization fractions, $N\left(X^{n+}\right) / N(X)$, of carbon ions in the coronal approximation.
TABLE 8

IONIZATION FRACTIONS OF NITROGEN IONS

\begin{tabular}{|c|c|c|c|c|c|c|c|c|}
\hline \multirow[b]{2}{*}{$\log _{10} T$} & \multicolumn{8}{|c|}{$N\left(X^{n+}\right) / N(X)$} \\
\hline & $\mathrm{N}_{\mathrm{I}}$ & $\mathrm{N}$ II & $\mathrm{N}$ III & $\mathrm{N}$ IV & $\mathrm{N} \mathrm{v}$ & $\mathrm{N}$ VI & N VII & N VIII \\
\hline $3.5 \ldots \ldots$ & $\ldots$ & $\ldots$ & $\ldots$ & $\cdots$ & $\ldots$ & $\ldots$ & $\ldots$ & $\ldots$ \\
\hline $3.6 \ldots \ldots$ & $\ldots$ & $\ldots$ & $\ldots$ & $\ldots$ & $\ldots$ & $\cdots$ & $\ldots$ & $\ldots$ \\
\hline $3.7 \ldots \ldots$ & & & $\cdots$ & $\cdots$ & $\cdots$ & $\cdots$ & $\cdots$ & $\cdots$ \\
\hline $3.8 \ldots \ldots$ & 0.00 & 7.45 & $\ldots$ & $\ldots$ & $\ldots$ & $\ldots$ & $\ldots$ & $\ldots$ \\
\hline $3.9 \ldots \ldots$ & 0.00 & 4.95 & $\ldots$ & $\ldots$ & $\ldots$ & $\ldots$ & $\ldots$ & $\ldots$ \\
\hline $4.0 \ldots \ldots$ & 0.00 & 2.95 & $\ldots$ & $\ldots$ & $\ldots$ & $\ldots$ & $\cdots$ & $\cdots$ \\
\hline $4.1 \ldots \ldots$ & 0.02 & 1.37 & & $\ldots$ & $\ldots$ & $\ldots$ & $\ldots$ & $\ldots$ \\
\hline $4.2 \ldots \ldots$ & 0.25 & 0.35 & 6.65 & $\ldots$ & $\ldots$ & $\ldots$ & $\ldots$ & $\ldots$ \\
\hline $4.3 \ldots \ldots$ & 0.89 & 0.06 & 4.37 & $\ldots$ & $\ldots$ & $\ldots$ & $\ldots$ & $\ldots$ \\
\hline $4.4 \ldots \ldots$ & 1.46 & 0.02 & 2.79 & 9.84 & $\ldots$ & $\ldots$ & $\ldots$ & $\ldots$ \\
\hline $4.5 \ldots \ldots$ & 1.86 & 0.02 & 1.66 & 6.74 & $\ldots$ & $\ldots$ & $\ldots$ & $\ldots$ \\
\hline $4.6 \ldots \ldots$ & 2.21 & 0.07 & 0.87 & 4.45 & & $\ldots$ & $\ldots$ & $\ldots$ \\
\hline $4.7 \ldots \ldots$ & 2.63 & 0.23 & 0.38 & 2.80 & 9.00 & $\ldots$ & $\ldots$ & $\ldots$ \\
\hline $4.8 \ldots \ldots$ & 3.18 & 0.55 & 0.16 & 1.65 & 6.24 & $\ldots$ & $\ldots$ & $\ldots$ \\
\hline $4.9 \ldots \ldots$ & 3.82 & 0.98 & 0.12 & 0.87 & 4.13 & 8.02 & $\ldots$ & $\ldots$ \\
\hline $5.0 \ldots \ldots$ & 4.58 & 1.53 & 0.26 & 0.38 & 2.57 & 5.06 & $\ldots$ & $\ldots$ \\
\hline $5.1 \ldots \ldots$ & 5.46 & 2.20 & 0.57 & 0.16 & 1.45 & 2.82 & $\ldots$ & $\ldots$ \\
\hline $5.2 \ldots \ldots$ & 6.47 & 3.00 & 1.05 & 0.18 & 0.73 & 1.18 & $\ldots$ & $\ldots$ \\
\hline $5.3 \ldots \ldots$ & 7.85 & 4.18 & 1.93 & 0.67 & 0.59 & 0.29 & $\ldots$ & $\ldots$ \\
\hline $5.4 \ldots \ldots$ & 9.59 & 5.73 & 3.20 & 1.59 & 0.98 & 0.06 & 9.96 & $\ldots$ \\
\hline $5.5 \ldots \ldots$ & $\ldots$ & 7.22 & 4.44 & 2.51 & 1.45 & 0.02 & 7.54 & $\ldots$ \\
\hline $5.6 \ldots \ldots$ & $\ldots$ & 8.55 & 5.53 & 3.32 & 1.87 & 0.01 & 5.60 & \\
\hline $5.7 \ldots \ldots$ & $\ldots$ & 9.72 & 6.48 & 4.02 & 2.23 & 0.00 & 4.03 & 9.62 \\
\hline $5.8 \ldots \ldots$ & $\ldots$ & $\ldots$ & 7.30 & 4.61 & 2.51 & 0.00 & 2.75 & 6.85 \\
\hline $5.9 \ldots \ldots$ & $\ldots$ & $\ldots$ & 7.98 & 5.06 & 2.70 & 0.01 & 1.73 & 4.62 \\
\hline $6.0 \ldots \ldots$ & $\ldots$ & $\ldots$ & 8.53 & 5.41 & 2.80 & 0.05 & 0.98 & 2.88 \\
\hline $6.1 \ldots \ldots$ & $\ldots$ & $\ldots$ & 9.06 & 5.76 & 2.92 & 0.17 & 0.52 & 1.61 \\
\hline $6.2 \ldots \ldots$ & $\ldots$ & $\ldots$ & 9.69 & 6.20 & 3.16 & 0.42 & 0.34 & 0.77 \\
\hline $6.3 \ldots \ldots$ & $\ldots$ & $\ldots$ & $\ldots$ & 6.81 & 3.58 & 0.85 & 0.43 & 0.31 \\
\hline $6.4 \ldots \ldots$ & $\ldots$ & $\ldots$ & $\ldots$ & 7.56 & 4.15 & 1.39 & 0.70 & 0.12 \\
\hline $6.5 \ldots \ldots$ & $\ldots$ & $\ldots$ & $\ldots$ & 8.34 & 4.76 & 1.95 & 1.02 & 0.05 \\
\hline $6.6 \ldots \ldots$ & $\ldots$ & $\ldots$ & $\ldots$ & 9.10 & 5.35 & 2.48 & 1.32 & 0.02 \\
\hline $6.7 \ldots \ldots$ & $\ldots$ & $\ldots$ & $\ldots$ & 9.82 & 5.92 & 2.96 & 1.59 & 0.01 \\
\hline $6.8 \ldots \ldots$ & $\ldots$ & $\ldots$ & $\ldots$ & $\ldots$ & 6.46 & 3.41 & 1.83 & 0.01 \\
\hline $6.9 \ldots \ldots$ & $\ldots$ & $\ldots$ & $\ldots$ & $\ldots$ & 6.98 & 3.81 & 2.05 & $\ldots$ \\
\hline $7.0 \ldots \ldots$ & $\ldots$ & $\ldots$ & $\ldots$ & $\ldots$ & 7.47 & 4.18 & 2.24 & $\ldots$ \\
\hline $7.1 \ldots \ldots$ & $\ldots$ & $\ldots$ & $\ldots$ & $\ldots$ & 7.94 & 4.53 & 2.41 & $\ldots$ \\
\hline $7.2 \ldots \ldots$ & $\ldots$ & $\ldots$ & $\ldots$ & $\ldots$ & 8.39 & 4.86 & 2.57 & $\ldots$ \\
\hline $7.3 \ldots \ldots$ & $\ldots$ & $\ldots$ & $\ldots$ & $\ldots$ & 8.83 & 5.17 & 2.71 & $\ldots$ \\
\hline $7.4 \ldots \ldots$ & $\ldots$ & $\ldots$ & $\ldots$ & $\ldots$ & 9.25 & 5.46 & 2.85 & $\ldots$ \\
\hline
\end{tabular}

NoTE.- Ionization fractions, $N\left(X^{n+}\right) / N(X)$, of nitrogen ions in the coronal approximation. 

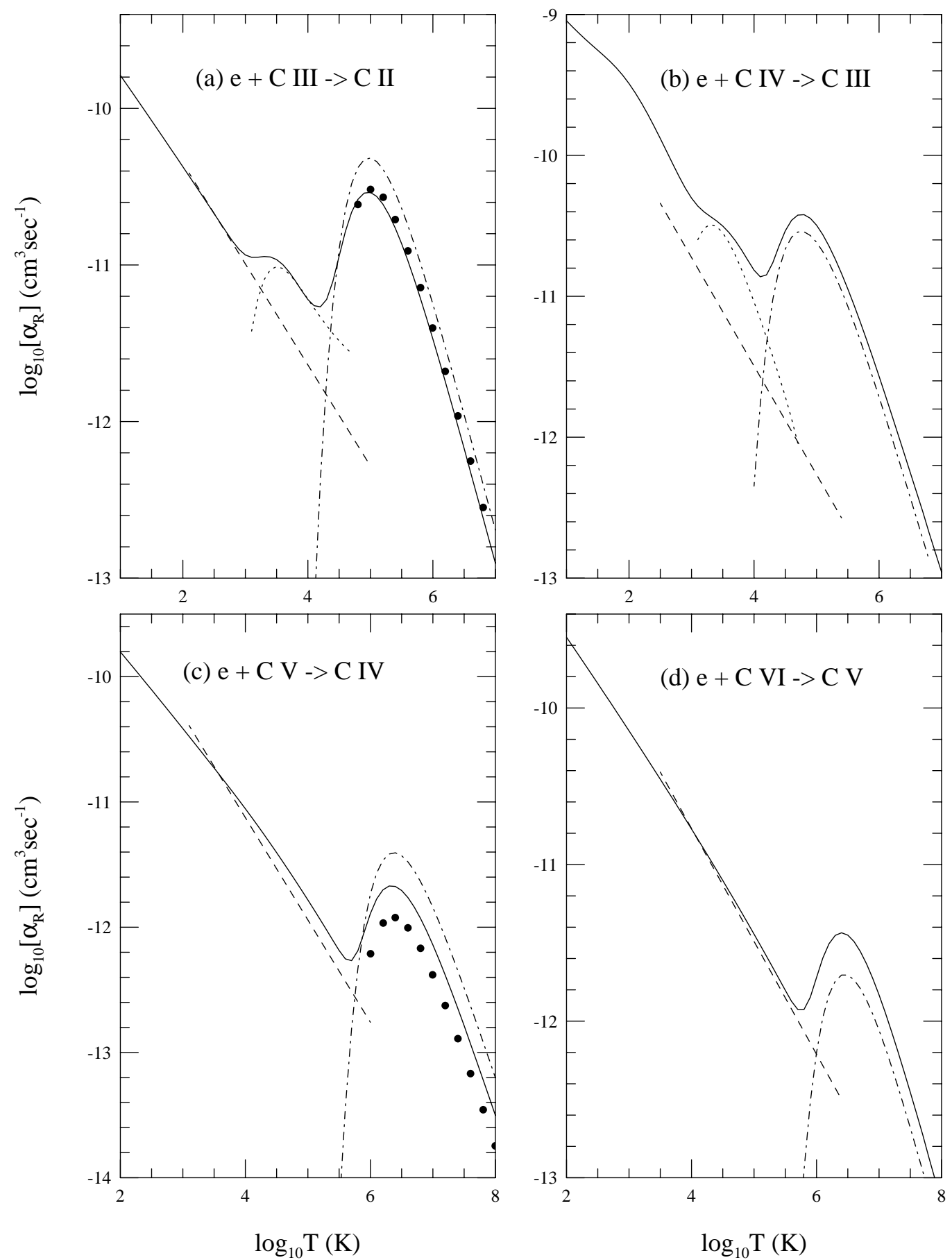

Fig. 7.-Total recombination rate coefficients, $\alpha_{R}(T)$, of $(a) \mathrm{C}$ II, $(b) \mathrm{C} \mathrm{III,}(c) \mathrm{C}$ IV, and $(d) \mathrm{C} \mathrm{v}$ from the present work (solid lines). The dashed lines represent the RR rates calculated by Aldrovandi \& Pequignot (1973), the dotted lines represent low-temperature DR by Nussbaumer \& Storey (1983), and the dot-dashed lines represent fits for high-temperature DR by Shull \& Steenberg 1982a, 1982b. The filled circles are calculated DR rates for C II by Badnell (1987) and for C IV by Badnell et al. (1990). 

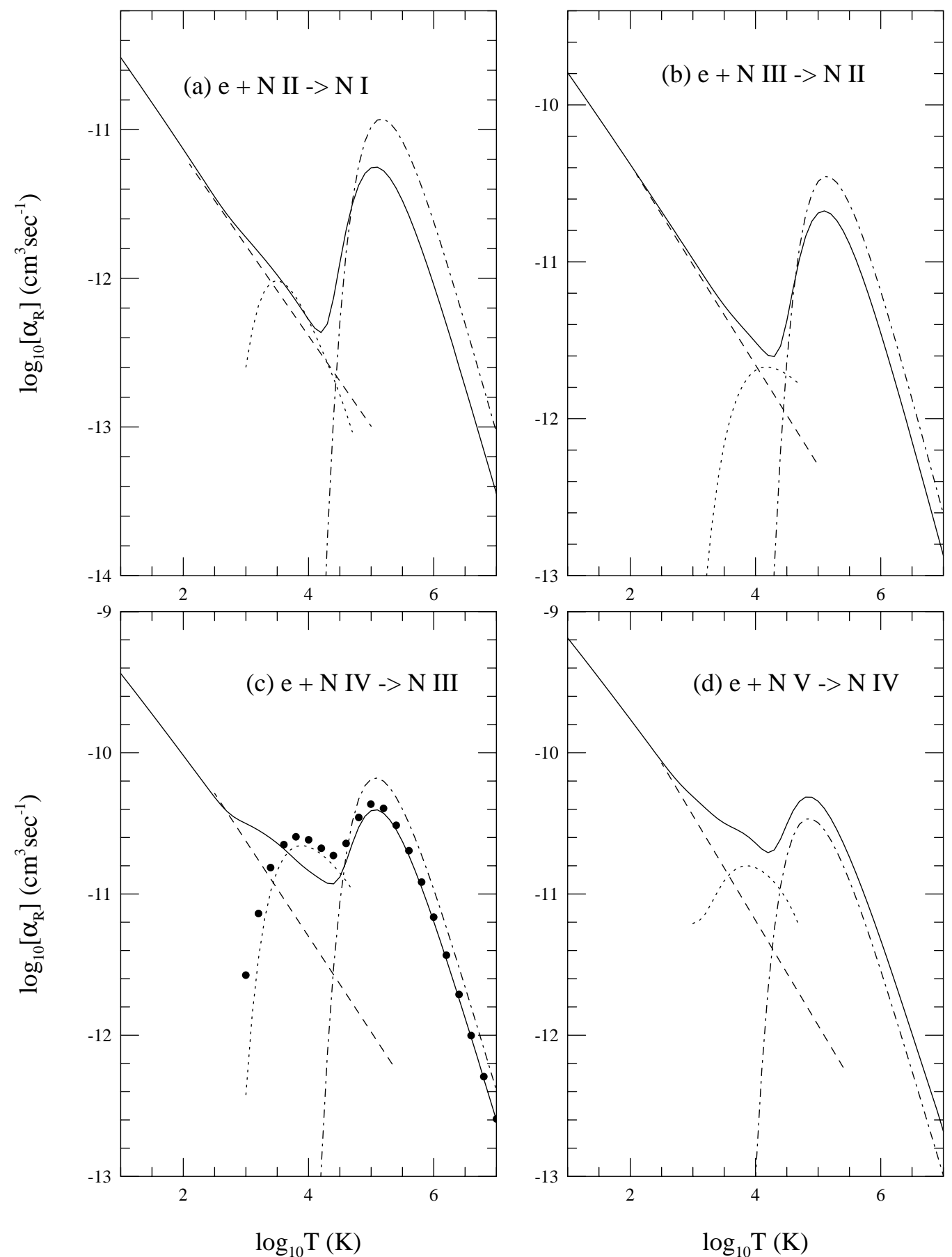

FIG. 8. - Same as Fig. 7, except for $(a) \mathrm{N} \mathrm{I},(b) \mathrm{N}$ II, $(c) \mathrm{N}$ III, $(d) \mathrm{N}$ IV, $(e) \mathrm{N}$ v, and $(f) \mathrm{N}$ vi. The filled circles are calculated values by Badnell (1987, 1988). 

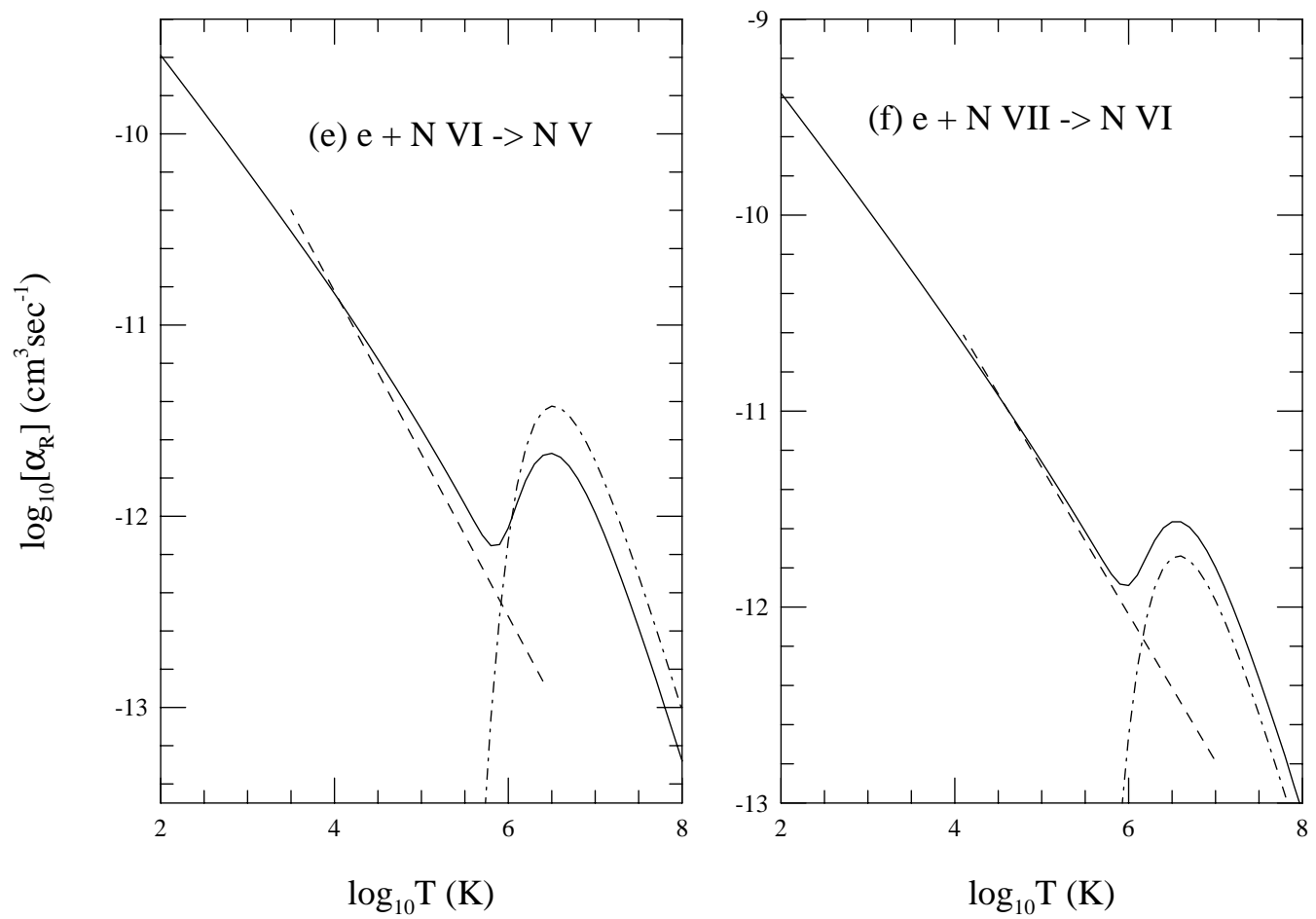

FIG. 8-Continued

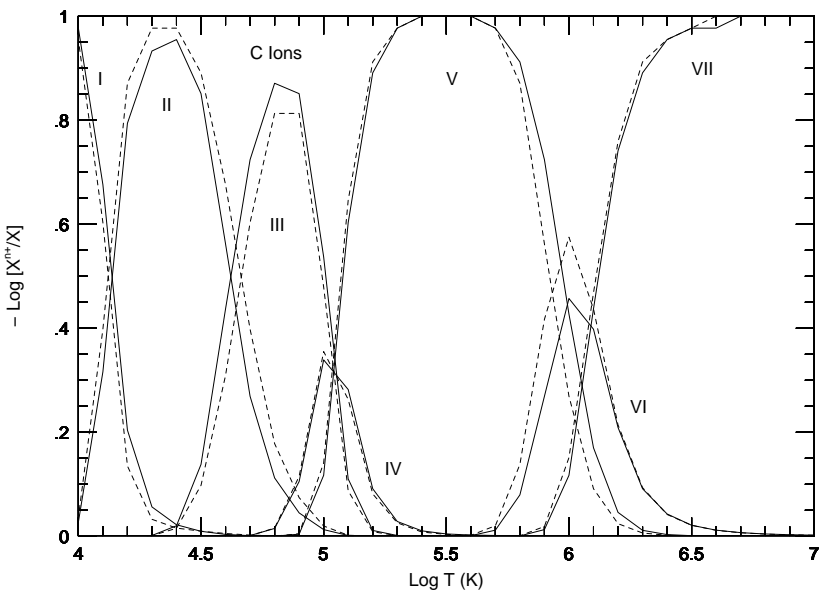

FIG. 9.-Ionization fractions, $\left[N\left(X^{z}\right) / N(X)\right](T)$, of carbon ions: present work, using the present electron-ion recombination rates (solid lines), and Arnaud \& Rothenflug (1985; dashed lines). $N(\mathrm{X})$ is the total carbon abundance.

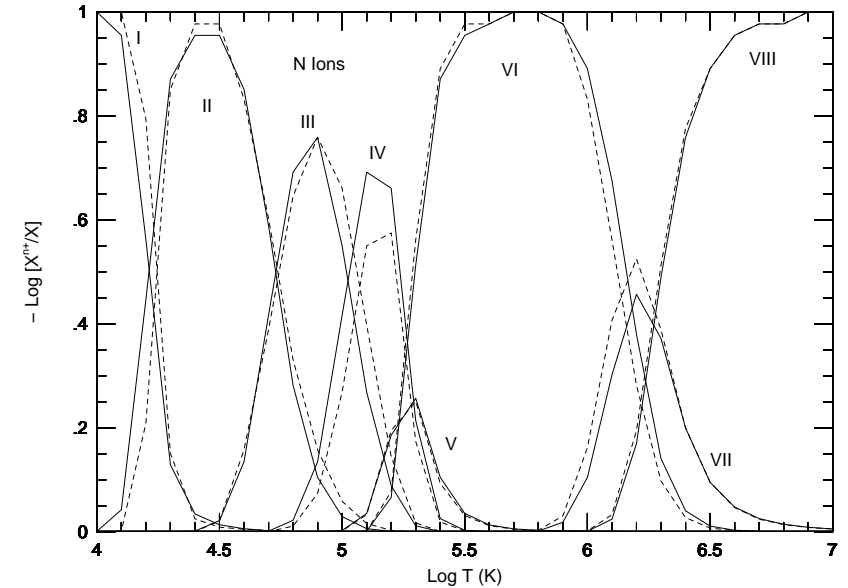

FIG. 10.- Ionization fractions, $\left[N\left(X^{z}\right) / N(X)\right](T)$, of nitrogen ions: present work, using the present electron-ion recombination rates (solid lines), and Arnaud \& Rothenflug (1985; dashed lines). $N(\mathrm{X})$ is the total nitrogen abundance.
Aldrovandi, S. M. V., \& Pequignot, D. 1973, A\&A, 25, 137

Arnaud, M., \& Rothenflug, R. 1985, A\&AS, 60, 425

Badnell, N. R. 1987, J. Phys. B, 20, 2081

1988, J. Phys. B, 21, 749

Badneli, N. R., Pindzola, M. S., \& Griffin, D. C. 1990, Phys. Rev. A, 41, 2422

Bell, K. L., Gilbody, H. B., Hughes, J. G., Kingston, A. E., \& Smith, F. J. 1983, J. Phys. Chem. Ref. Data, 12(4), 891

Bell, R. H., \& Seaton, M. J. 1985, J. Phys. B, 18, 1589

Berrington, K. A., Burke, P. G., Butler, K., Seaton, M. J., Storey, P. J., Taylor, K. T., \& Yan, Yu. 1987, J. Phys. B, 20, 6379

Burgess, A. 1965, ApJ, 141, 1588

Burke, V. M., \& Lennon, D. J. 1996, Data available at TOPbase

Cunto, W., Mendoza, C., Ochsenbein, F., \& Zeippen, C. J. 1993, A\&A, 275, L5

Eissner, W., Jones, M., \& Nussbaumer, H. 1974, Comput. Phys. Commun., 8,270

Fernley, J. A., Hibbert, A., Kingston, A. E., \& Seaton, M. J. 1996, Data available at TOPbase (F1)

\section{REFERENCES}

Fernley, J. A., Taylor, K. T., \& Seaton, M. J. 1987, J. Phys. B, 20, 6457 (F2) Hummer, D. G., Berrington, K. A., Eissner, W., Pradhan, A. K., Saraph, H. E., \& Tully, J. A. 1993, A\&A, 279, 298

Jacobs, V. L., Davis, J., Rogerson, J. E., \& Blaha, M. 1978, J. Quant. Spectrosc. Radiat. Transfer, 19, 991

Jacobs, V. L., Davis, J., Rogerson, J. E., Blaha, M., Cain, J., \& Davis, M. 1980, ApJ, 239, 1119

Le Dourneuf, M., Lan, V. K., \& Hibbert, A. 1976, J. Phys. B, 12, L359

Le Dourneuf, M., Lan, V. K., \& Zeippen, C. J. 1979, J. Phys. B, 12, 2449

Lennon, M. A., Bell, K., Gilbody, H. B., Hughes, J. G., Kingston, A. E.,

Murray, M. J., \& Smith, F. J. 1988, J. Phys. Chem. Ref. Data, 17(3), 1285

Luo, D., \& Pradhan, A. K. 1989, J. Phys. B, 22, 3377

Nahar, S. N. 1995, ApJS, 101, 423

Nahar, S. N. 1996a, ApJS, 106, 213

1996b, Phys. Rev. A, 53, 2417

1997, Phys. Rev. A, 55, 1980

Nahar, S. N., Bautista, M. A., \& Pradhan, A. K. 1997a, ApJ, 479, 497

Nahar, S. N., \& Pradhan, A. K. 1991, Phys. Rev. A, 44, 2935 . 1994, Phys. Rev. A, 49, 1816 
Nahar, S. N., \& Pradhan, A. K. 1995, ApJ, 447, 966 (NP)

Nahar, S. N., Zhang, H. L., \& Pradhan, A. K. 1997b, Phys. Rev. A, submitted

Nussbaumer, H., \& Storey, P. J. 1983, A\&A, 126, 75

Opacity Project Team. 1995, The Opacity Project, Vol. 1 (London: Inst. Phys. Publ.)

Osterbrock, D. E. 1989, Astrophysics of Gaseous Nebulae and Active Galactic Nuclei (Mill Valley: University Science)

Peach, G., Saraph, H. E., \& Seaton, M. J. 1988, J. Phys. B, 21, 3669

Reilman, R. F., \& Manson, S. T. 1979, ApJS, 40, 815

Samson, J. A. R., \& Angel, G. C. 1990, Phys. Rev. A, 42, 1307
Seaton, M. J. 1987, J. Phys. B, 20, 6363

1996, Data available at TOPbase

Seaton, M. J., Yu, Y., Mihalas, D., \& Pradhan, A. K. 1994, MNRAS, 266, 805

Shull, J. M., \& van Steenberg, M. 1982a, ApJS, 48, 95 $1982 \mathrm{~b}, \mathrm{ApJS}, 49,351$

Storey, P. J., \& Hummer, D. G. 1992, Comput. Phys. Commun., 66, 129

Sutherland, R. S., \& Dopita, M. A. 1993, ApJS, 88, 253

Tully, J. A., Seaton, M. J., \& Berrington, K. A. 1990, J. Phys. B, 23, 3811

Zhang, H. L., \& Pradhan, A. K. 1997, Phys. Rev. Lett., 78, 195 